\author{
UNIVERSIDADE DE SÃO PAULO \\ ESCOLA DE ENGENHARIA DE SÃO CARLOS \\ DEPARTAMENTO DE HIDRÁULICA E SANEAMENTO \\ PROGRAMA DE PÓS-GRADUAÇÃO EM CIÊNCIAS DA ENGENHARIA \\ AMBIENTAL
}

\title{
CONTROLE DO PROCESSO DA TRANSFERÊNCIA DE OXIGÊNIO EM CORPOS HÍDRICOS
}

\section{LUIZ CARLOS CORRÊA}

\author{
Orientador: Prof. Dr. Nivaldo Aparecido Corrêa
}

São Carlos

2006 


\title{
CONTROLE DO PROCESSO DA TRANSFERÊNCIA DE OXIGÊNIO EM CORPOS HÍDRICOS
}

\author{
LUIZ CARLOS CORRÊA
}

Dissertação apresentada à Escola de Engenharia de São Carlos da Universidade de São Paulo, como parte dos requisitos para a obtenção do Título de Mestre em Ciências da Engenharia Ambiental.

ORIENTADOR: Prof. Dr. Nivaldo Aparecido Corrêa

São Carlos

2006 
AUTORIZO A REPRODUÇÃO E DIVULGAÇÃO TOTAL OU PARCIAL DESTE TRABALHO, POR QUALQUER MEIO CONVENCIONAL OU ELETRÔNICO, PARA FINS DE ESTUDO E PESQUISA, DESDE QUE CITADA A FONTE.

Ficha catalográfica preparada pela Seção de Tratamento da Informação do Serviço de Biblioteca - EESC/USP

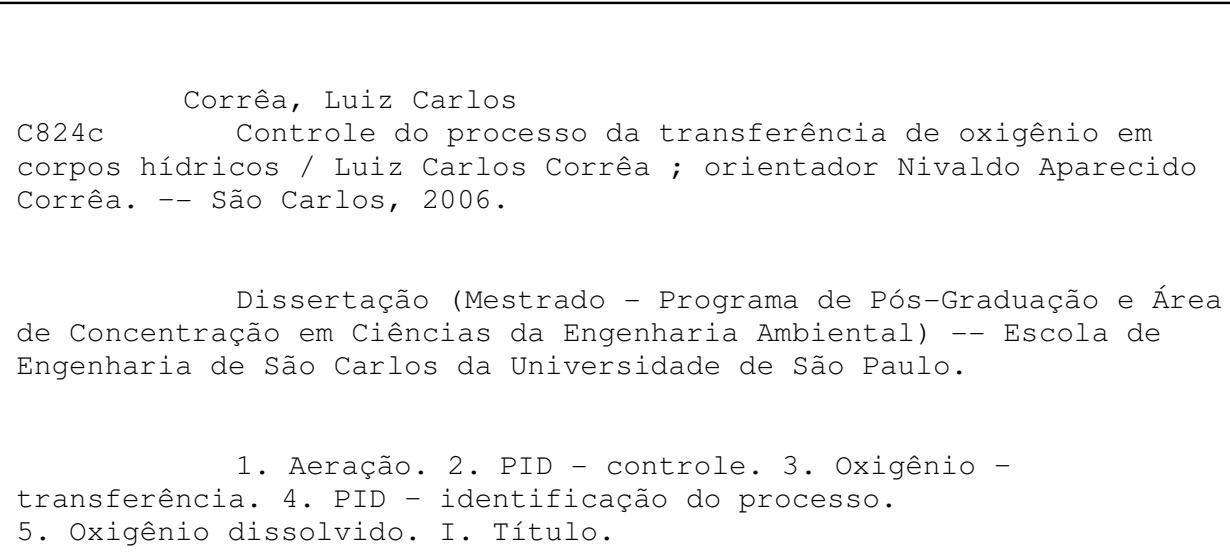




\section{FOLHA DE JULGAMENTO}

\section{Candidato: Bacharel LUIZ CARLOS CORRÊA}

Dissertação defendida e julgada em 23/10/2006 perante a Comissão Julgadora:

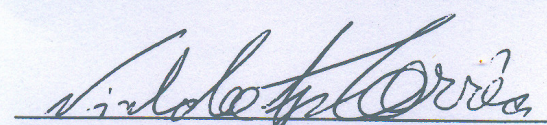

Prof. Dr. NIVALIO APARECIDO CORRÊA (Orientador)

(Escola de Engenharia de 5\% Carlós/USP)

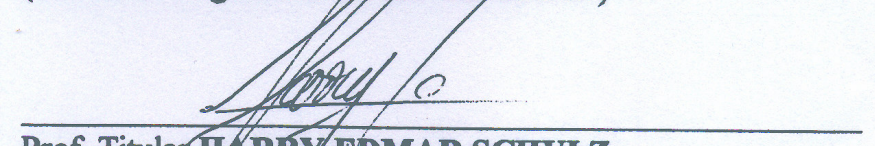

Prof. Titular HARY EDMAR SCHULZ

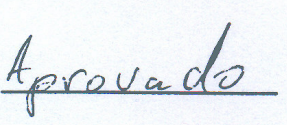

(Escola de Engenharia de São Carlos/USP)

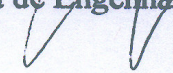

Clixamdn Grandizo

Prof. Dr. ALEXANDRE AIR GONDIZO

(Universidade de Franca/UNIFRAN)
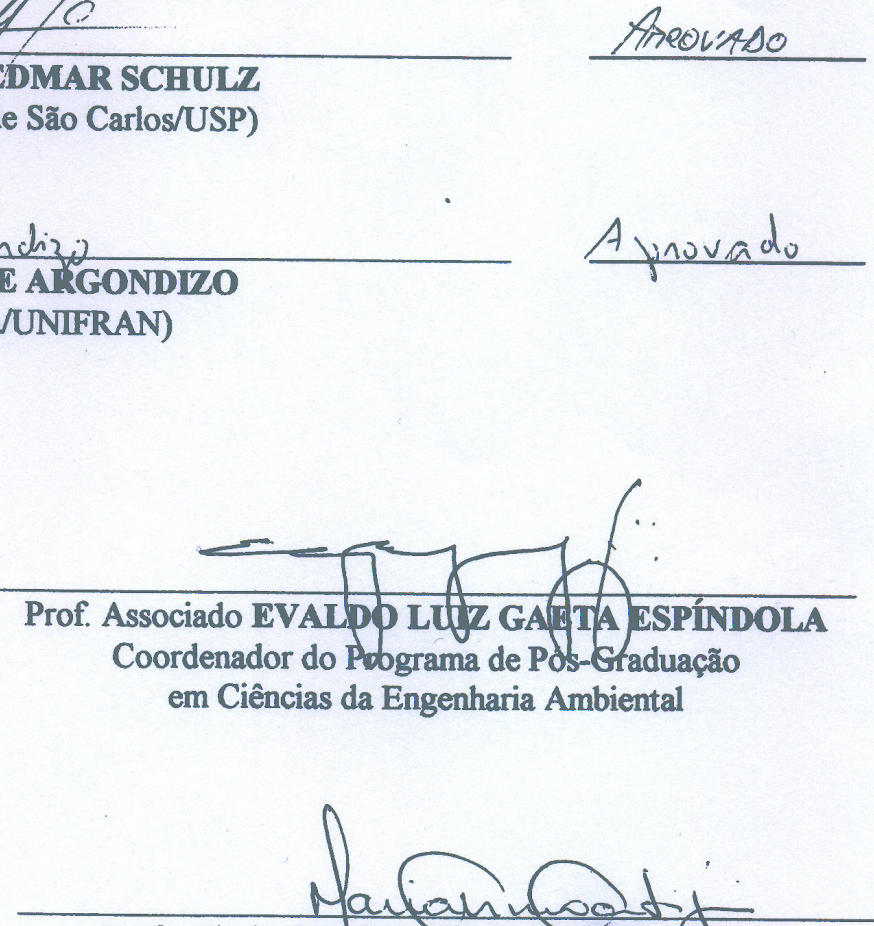

Profa. Titular MARIA DO CARMO CALAUURI

Presidente da Comissão de Pós-Graduação 


\section{DEDICATÓRIA}

A Deus, pela força e proteção em todos os momentos.

E às pessoas que mais amo:

Ao meu pai Luiz Corrêa (in memorium) pelo amor e dedicação, que sempre ficarão guardados em mim. À minha mãe Regina A. Corrêa que, mesmo nas dificuldades do cotidiano, jamais perde a fé na vida - maneira de ser que sempre tentarei imitar.

Ao meu irmão Flávio; sem o seu sorriso o mundo certamente seria mais triste.

Ao meu outro irmão Paulo, um amigo.

À minha irmã Raquel, sempre com pureza na alma e espírito de doação. 


\section{AGRADECIMENTOS}

Ao professor Nivaldo Aparecido Corrêa, grande professor e orientador deste trabalho, com quem tenho a honra de poder compartilhar da amizade e a felicidade de contar com a preciosa orientação, cuja condução é e será sempre para mim um exemplo a ser seguido; e, ainda pela confiança e amizade. Mostrou-me que os dons inatos de nada valem sem a força do espírito que se dispõe a aprender. Não há limites para a vontade interior, quando combinada a um treinamento consistente. Como um grande líder, sabe como ninguém desenvolver o potencial dos que trabalham como ele.

Ao professor Harry Edmar Schulz, a quem devo parte da minha formação quando aluno da pós-graduação. Obrigado pela confiança depositada.

Aos professores Dr. Alexandre Argondizo e Sérgio Rocha, pelo incentivo e contribuição nas importantes críticas e sugestões no decorrer do trabalho de pesquisa.

À professora Ruth de Gouvêa Duarte, disposta a auxiliar-me com minhas dúvidas de redação e interpretação.

Aos professores, funcionários e alunos de Pós-Graduação do Centro de Recursos Hídricos e Ecologia Aplicada ( CRHEA/SHS ) da Escola de Engenharia de São Carlos, que foram e são de fundamental importância para a construção de novas amizades. 
Aos amigos com quem pude conviver muitos momentos felizes e força: Isabel Martins, Rosana Amor, Maria Regina, Mariká, Miguel, Matheus, Tony e ao Emílio e a todos os outros.

Ao CNPq, pela concessão financeira instituída na forma de bolsa de mestrado.

À FAPESP, pela concessão financeira de equipamento e suporte computacional. 


\section{SUMÁRIO}

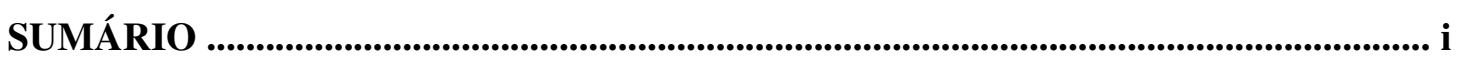

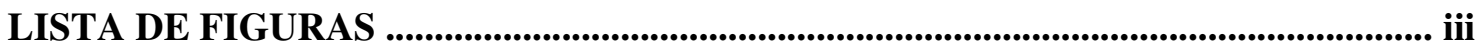

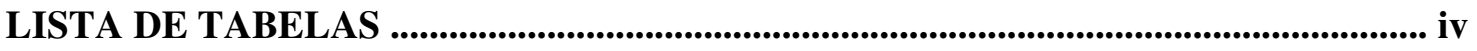

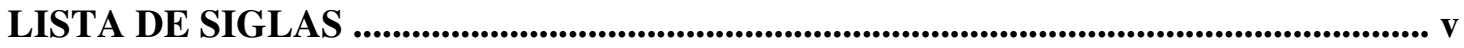

LISTA DE SÍMBOLOS ................................................................................................... vi

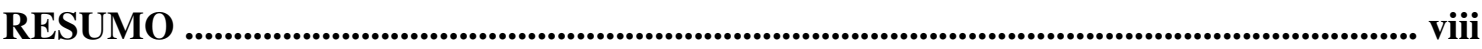

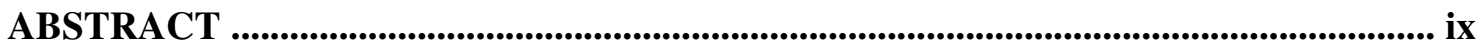

1. INTRODUÇÃO .................................................................................................................... 1

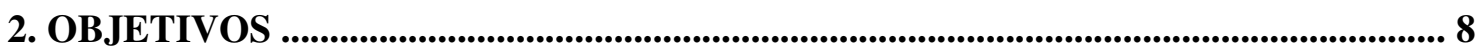

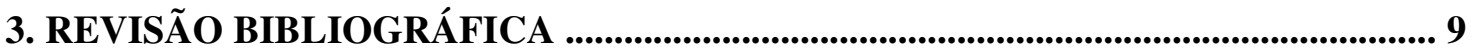

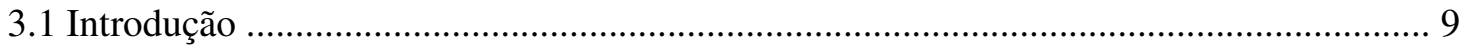

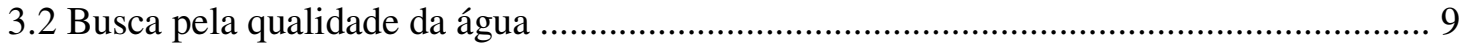

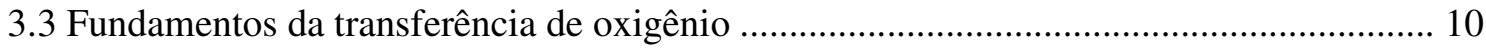

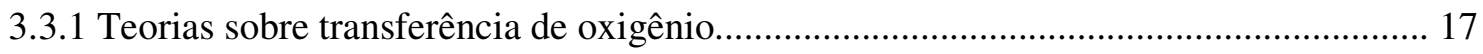

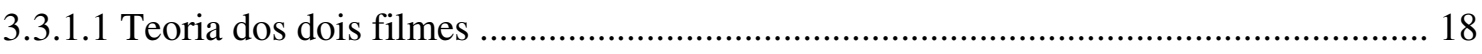

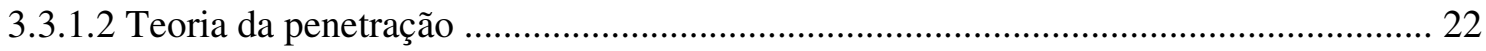

3.3.1.3 Teoria da renovação superficial ........................................................................ 24

3.4 Fatores que afetam a transferência de oxigênio ............................................................ 25

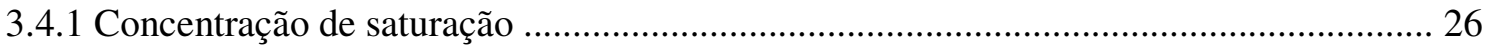

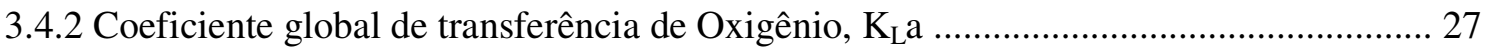

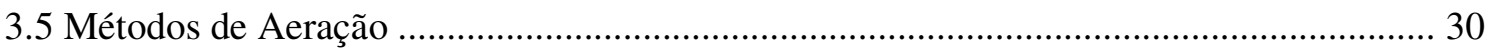




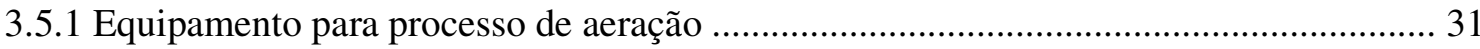

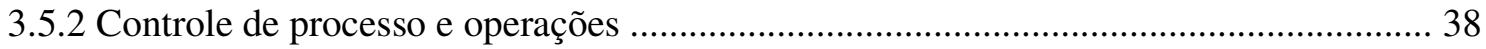

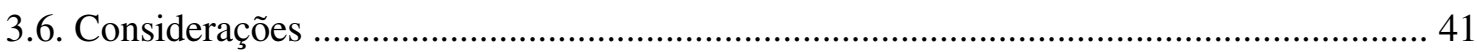

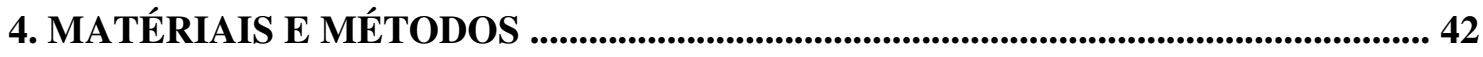

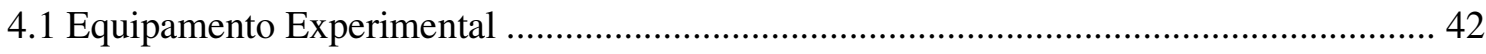

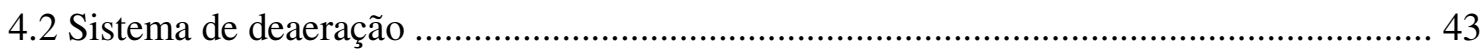

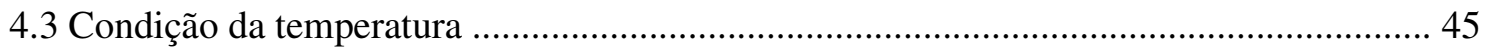

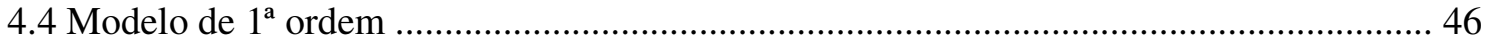

4.5 Calibração do medidor de vazão (placa de orifício) ........................................................ 46

5 RESULTADOS E DISCUSSÕES................................................................................. 49

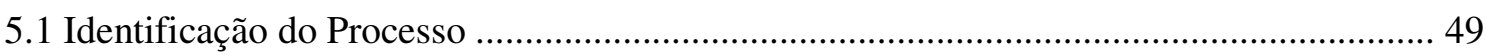

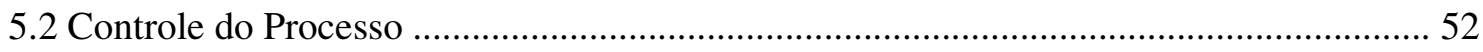

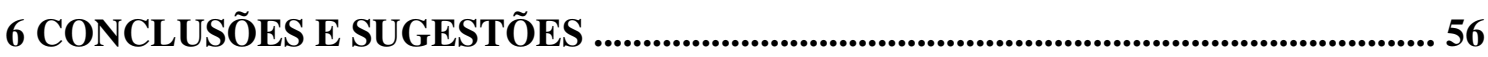

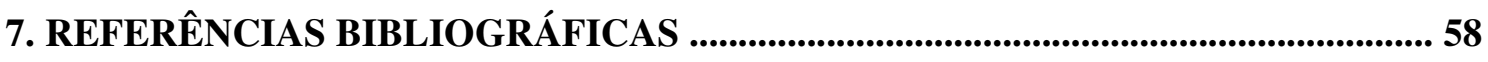

APÊNDICE A 


\section{LISTA DE FIGURAS}

FIGURA 1 - Diagrama esquemático da transferência gás-líquido proposta pela teoria dos dois

filmes.

FIGURA 2 - Equipamentos típicos para aeração por ar difuso 34

FIGURA 3 - Planta experimental do tanque de aeração adaptado de um canal aberto. Dimensões. Disposição do sistema para aquisição de dados e controle 43

FIGURA 4 - Sistema de deaeração da água. 45

FIGURA 5 - Curva de calibração do medidor de vazão (placa de orifício)...... 47

FIGURA 6 - Perturbação para degrau positivo na rotação.

FIGURA 7 - Resposta ao degrau positivo. Azul-dados experimentais. Verde: ajuste pelo modelo de $1^{\mathrm{a}}$ ordem 50

FIGURA 8 - Perturbação para degrau negativo na rotação. 51

FIGURA 9 - Resposta ao degrau negativo. Azul-dados experimentais. Verde: ajuste pelo modelo $1^{\mathrm{a}}$ ordem. 51

FIGURA 10 - Controle PID. Mudança de "set-point” em degrau negativo de $9 \%$ 53

FIGURA 11 - Controle PID. Mudança de "set-point" em degraus positivos de

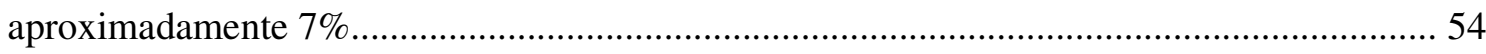

FIGURA 12 - Controle PID. Distúrbio na carga vazão em degrau negativo de 50\% 


\section{LISTA DE TABELAS}

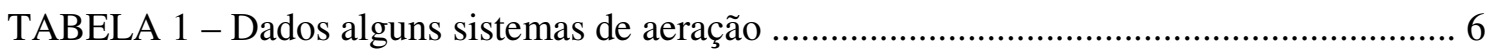

TABELA 2 - Resumo dos fatores do coeficiente volumétrico de transferência de oxigênio e da concentração de saturação do oxigênio na água ................................................................ 12

TABELA 3 - Coeficiente para correção de $\mathrm{K}_{\mathrm{La}}$ com a temperatura...................................... 28

TABELA 4 - Descrição de alguns equipamentos para aeração por ar difuso ......................... 33 


\section{LISTA DE SIGLAS}

AAS - Alternating Actived Sludge

AD/DA - Analógico para digital / Digital para Analógico

ASCE - American Society of Civil Engineers

CRHEA - Centro de Recursos Hídricos e Ecologia Aplicada

CONAMA - Conselho Nacional do Meio Ambiente

DMC - Dynamic Matrix Control (Controle Matriz Dinâmica )

EESC - Escola de Engenharia de São Carlos

EIMCO - Companhia de Equipamentos de Processo

ITAE - Integral of the time-weighted absolute

MPC - Model Predictive Control ( Controle do Modelo Preditivo )

OD - Oxigênio dissolvido

ONU - Organização Nações Unidas

OMS - Organização Mundial da Saúde

PID - Proportional Integral Derivative ( Proporcional Integral Derivativa)

QP - Programação Quadrática

QDMC - Quadratic Dynamic Matrix Control ( Controle da Matriz Dinâmica Quadrática)

SISO - simples entrada - simples saída

USP - Universidade de São Paulo 


\section{LISTA DE SÍMBOLOS}

\section{Concernentes ao controle}

$A(t-\Delta t) \cdot \Delta t] . r_{S} \cdot \Delta t=$ quantidade de área renovada no tempo $\Delta t$

$A(t)=$ Constante $\cdot \exp \left[-\mathrm{r}_{\mathrm{S}} . \mathrm{t}\right]$

$A=$ área interfacial para a transferência $\mathrm{L}^{2}$;

$A=$ amplitude do degrau na variável de entrada (rpm)

$B=$ parâmetros do modelo linear relacionado à variável de entrada ;

$C=$ matriz gerada pela reformulação das restrições $\left(\mathrm{MLl}^{-3}\right)$;

$C s=$ concentração de saturação de oxigênio dissolvido na água limpa $\left(\mathrm{ML}^{-3}\right)$;

$C_{0}=$ concentração inicial de oxigênio dissolvido $\left(\mathrm{ML}^{-3}\right)$;

$C=$ concentração de oxigênio dissolvido no seio líquido termo dependente do tempo- $\left(\mathrm{ML}^{-3}\right)$,

$C_{S}\left(P_{b}\right)=$ concentração de saturação de $O D$ à pressão atmosférica nas condições experimentais

$C_{S}\left(P_{S}\right)=$ concentração de saturação de $O D$ à pressão padrão total de 1 atm com umidade relativa de $100 \%\left(\mathrm{ML}^{-3}\right)$

$C_{S}{ }^{`}=$ concentração de equilíbrio na água sob condições de processo $\left(\mathrm{ML}^{-3}\right)$;

$C i=$ concentração de oxigênio na interface líquida $\left(\mathrm{ML}^{-3}\right)$;

$C_{L}=$ concentração de oxigênio no meio líquido $\left(\mathrm{ML}^{-3}\right)$;

$\mathrm{C}^{*}$ e $\mathrm{P}^{*}=$ concentrações de equilíbrio $\left(\mathrm{ML}^{-3}\right)$;

$C_{S}=$ concentração de saturação do oxigênio na interface $\left(\mathrm{ML}^{-3}\right)$;

$C_{t}=$ concentração de oxigênio dissolvido no resíduo, em função do tempo( $\left(\mathrm{ML}^{-3}\right)$;

$d C / d t=$ taxa de transferência de oxigênio (adimensional)

$d_{e}=$ profundidade da saturação efetiva ao tempo infinito L;

$D=$ difusividade molecular do oxigênio na água $\left(\mathrm{ML}^{-3}\right)$;

$e=$ desvio da variável de saída com relação ao "set-point" $\left(e=y_{s p}-y\right)$;

$f=$ fator de ponderação para $\Delta u$;

$H=$ constante de Henry.

$K_{L} a=$ coeficiente volumétrico global de transferência de oxigênio $\left(\mathrm{ML}^{-3}\right)$

$K_{L} a_{T}=$ coeficiente volumétrico de transferência de massa para água sob condições de processo à tempertura $\mathrm{T}\left(\mathrm{ML}^{-3}\right)$;

$K_{L} a_{20}=$ coeficiente volumétrico de transferência de massa para água limpa à temperatura de $20^{\circ} \mathrm{C}\left(\mathrm{ML}^{-3}\right)$;

$K_{L} a^{`}=$ coeficiente volumétrico de transferência $\left(\mathrm{ML}^{-3}\right)$;

$\mathrm{K}_{1}$ e $\mathrm{K}_{\mathrm{g}}=$ coeficientes de transferência de massa para os filmes líquido e gasoso, e correspondem idealmente à $\mathrm{D} / \delta$, onde $\mathrm{D}$ é a difusividade molecular $\left(\mathrm{ML}^{-3}\right)$;

$K_{L}=$ coeficiente de transferência de massa global $\left(\mathrm{ML}^{-3}\right)$;

$K_{L}=$ coeficiente de transferência baseado no filme líquido (relacionado à taxa de renovação superficial) $\left(\mathrm{ML}^{-3}\right)$;

$K_{L} a_{(T)}=$ coeficiente de transferência na temperatura de operação $\left(\mathrm{ML}^{-3}\right)$;

$K_{L} a_{(20)}=$ coeficiente de transferência a $20^{\circ} \mathrm{C}\left(\mathrm{ML}^{-3}\right)$;

$K_{L} a=$ coeficiente de transferência global de oxigênio na água pura $\left(\mathrm{ML}^{-3}\right)$;

$K=$ ganho do processo $(\mathrm{ppm} / \mathrm{rpm})$ 
$M=$ massa de oxigênio transferido por unidade de tempo $\left(\mathrm{ML}^{-3}\right)$;

$P_{v T}=$ pressão de vapor saturado à temperatura $\mathrm{T}$ da água $\left(\mathrm{ML}^{-3} \mathrm{~T}\right)$;

$P_{b}=$ pressão atmosférica nas condições experimentais $\left(\mathrm{ML}^{-3}\right)$;

$P s=$ pressão padrão total de $1 \mathrm{~atm}$ com umidade relativa de $100 \%\left(\mathrm{ML}^{-3}\right)$;

$P_{b}=$ pressão parcial no meio gasoso $\left(\mathrm{ML}^{-3}\right)$;

$P_{i}=$ pressão parcial na interface $\left(\mathrm{ML}^{-3}\right)$;

$P^{*}=$ pressão parcial do oxigênio (para o $\operatorname{ar}=0,209$ x pressão total)

$p_{n}=$ sinal de saída do controlador PID;

$t_{e}=$ tempo que bolha demora a percorrer a distância equivalente ao seu próprio diâmetro (s).

$t=$ tempo (s)

$Y_{w T}=$ densidade de massa da água à temperatura $\mathrm{T}$

$\gamma=$ taxa de consumo de oxigênio dissolvido pelo sistema;

$Y=\operatorname{resposta}(\mathrm{ppm})$

$Y i=$ estado estacionário inicial (ppm)

$\delta=$ espessura do filme

grego

$\theta=$ constante que varia de sistema para sistema

$\theta=$ tempo de atraso (s);

$\tau=$ constante de tempo $(\mathrm{s})$

$\tau_{I}$-tempo de integração, ou intervalo de repetição da ação proporcional do PID (s);

$\tau_{D}$-tempo derivativo do PID.(s);

$\Delta u$ - movimentos da variável manipulada $\left(\mathrm{ML}^{-3}\right)$;

$\Delta u$ - vetor de movimentos da variável manipulada $\left(\mathrm{ML}^{-3}\right)$; 


\section{RESUMO}

CORRÊA, L. C. (2006). Controle do processo da transferência de oxigênio em corpos hídricos. Dissertação (Mestrado em Ciências da Engenharia Ambiental). Escola de Engenharia de São Carlos, Universidade de São Paulo, São Carlos, 2006. 95p

A presente proposta de estudo refere-se à identificação de modelo linear empírico para processo de transferência de oxigênio das bolhas de ar para o meio líquido, simulação para testes de controle e implementação de uma estratégia de controle em escala laboratorial em tempo real. Os ensaios de controle foram na unidade experimental (canal aberto) existente no Laboratório de Hidráulica Ambiental o qual foi adaptado para aeração com sensores, atuadores, microcomputador, interface AD/DA. Foi testado o algoritmo de controle do tipo convencional PID (“Proportional Integral Derivative” control). Com os resultados obtidos da perturbação degrau na variável de entrada (alimentação do ar) foi possível identificar o sistema como um modelo de $1^{\text {a }}$ ordem, suficiente para os propósitos de controle. Baseado na identificação, foi ajustado um controlador PID para implementação experimental. A principal contribuição desta pesquisa consistiu no emprego de uma estratégia de controle adequada na prática, ao processo de aeração.

Palavras chave: aeração, controle PID, transferência de oxigênio, oxigênio dissolvido, identificação do processo. 


\begin{abstract}
CORRÊA, L. C. (2006). Control of oxygen transfer in water bodies. São Carlos, 2006. Dissertação de Mestrado - Escola de Engenharia de São Carlos, Universidade de São Paulo. $95 \mathrm{p}$.

The current study refers to the identification of an empirical linear model for the oxygen transfer process from air bubbles to liquid, control tests simulation and implementation of a control strategy at real time in laboratory scale. The control tests were carried out at the experimental unit (open channel) located at the Environmental Hydraulic Laboratory which was adapted to aeration process with sensors, actuators, microcomputer, AD/DA interface. The classic PID (Proportional Integral Derivative control) algorithm was tested. With results from step response of input variable (air feeding) it was possible to identify the system as a first order model, enough for the control purposes. Based on the identification, a PID controller was adjusted for the experimental implementation. The main contribution of this work consisted of the employment of an appropriate control strategy to the aeration process in practice.
\end{abstract}

Key-words: aeration, PID control, oxygen transfer, dissolved oxygen, process identification 


\section{INTRODUÇÃO E JUSTIFICATIVA}

O crescente desenvolvimento das atividades humanas tem causado progressiva deterioração nos ecossistemas ecológicos e impactos ambientais. O ambiente tem sofrido ao longo dos anos alterações provocadas pela elevada quantidade de dejetos excedentes desses processos, os quais ultrapassam a capacidade suporte dos ecossistemas.

As alterações causadas aos sistemas naturais acarretam, a curto ou médio prazo, problemas em nível regional ou até mesmo mundial, de demanda e de qualidade dos recursos utilizados pelas populações humanas. A grande quantidade de materiais ou resíduos lançados no meio são preocupantes por causarem problemas de poluição do ar, água e solo. As causas ou fontes e as conseqüências imediatas e posteriores desses impactos nos ecossistemas têm provocado constante busca de soluções adequadas, por parte dos estudiosos ambientais.

A idéia de que os recursos naturais são inesgotáveis, infelizmente, persiste em "culturas desenvolvimentistas". Porém, nas últimas décadas tem sido dada relevante importância à conservação e melhoria da qualidade desses recursos, agora reconhecidos como esgotáveis. Quando um recurso é usado para diversos fins, é importante que ele seja protegido e programado para uso de maneira racional e eficiente.

A água apresenta um significativo destaque, pois sua manutenção em condições naturais de qualidade é absolutamente necessária a todo tipo de vida do planeta. A água possui múltiplos usos e a ONU e a OMS reconhecem todos eles como legítimos. Além do mais nobre dos usos dessedentação e higiene pessoal, ela é necessária à produção agrícola, 
indústria, geração de energia elétrica, assimilação de resíduos, recreação, navegação, produção de biomassa, apagar incêndios e uma variedade de outros propósitos. A demanda por água não envolve apenas considerações de sua quantidade, mas também e principalmente de sua qualidade. Sob esse aspecto, a qualidade do ambiente aquático pode ser definida por um conjunto de características físicas, químicas e biológicas. È importante ressaltar que a expressão corrente "qualidade da água" não se refere a um grau de pureza absoluto, que é um conceito limite, ou mesmo próximo do absoluto. Refere-se, sim, a um padrão tão próximo quanto possível do "natural", isto é, da água tal como se encontra nos rios e nascentes, antes do contato com o homem. Além disso, há um grau de pureza desejável, o qual depende do uso que dela será feito (abastecimento, irrigação, industrial, pesca etc).

Qualquer atividade humana pode ser considerada como fonte potencial de poluição da água, desde que ela possa causar variação na concentração e/ou nos padrões de qualidade das substâncias naturais nela encontradas. Similarmente, estas atividades podem introduzir novas substâncias ao sistema aquático, diretamente, através da atmosfera ou do ambiente terrestre.

O homem desenvolve atividades que têm grande impacto sobre a natureza dos ecossistemas aquáticos, como urbanização, desmatamento, irrigação, construção de represas, alterações de canais para navegação e mineração, despejos pontuais de efluentes domésticos e industriais, despejos não pontuais de agrotóxicos e fertilizantes originados das plantações agrícolas, entre outras.

Portanto, devido ao elevado grau de danos que a água tem sofrido, e em contrapartida, à crescente necessidade de utilização para diferentes fins, é preciso administrar sua disponibilidade e uso através de processo de gerenciamento. Esse gerenciamento deve incluir, de forma interativa e integrativa, uma visão inter e multidisciplinar do problema, articulando tecnologia, aspectos sócio-econômicos, saúde humana e bases científicas. Devido à complexa dependência dos processos relacionados ao ciclo hidrológico, à disponibilidade e uso da água, 
e a interações com a saúde humana, o manejo integrado deve apoiar-se nas bases biogeofísicas do sistema, representada pelas unidades naturais que são as bacias hidrográficas. Esta abordagem, cada vez mais, tem sido intensificada e sem dúvida deve ser considerada como processo fundamental no gerenciamento. Os recursos do solo, água e vegetação não podem ser satisfatoriamente manejados, quanto à disponibilidade e qualidade, de maneira isolada e independente um do outro (IRWIN \& WILLIAMS, 1986).

Dentro deste contexto, para se atingir os conhecimentos requeridos e então estabelecer um sistema de manejo, é significativamente necessário o acompanhamento das características e processos que, ao longo do tempo, ocorrem no corpo hídrico em questão. Assim é, clara a importância de um sistema de monitoramento da qualidade da água que, além de registrar as variações espaço-temporais, relacione de forma integrada os diversos mecanismos de interações do sistema em toda a sua bacia de drenagem.

A inter-relação entre uso da água e qualidade para ela requerida, é direta. Pode-se considerar que o uso mais nobre da água seja representado pelo abastecimento de água doméstico, o qual requer a satisfação de diversos critérios e padrões de qualidade. De forma oposta, pode-se considerar que o uso menos nobre seja a simples diluição de despejos, uma vez que a água não precisa satisfazer requisito algum de qualidade para este fim. No entanto, VON SPERLING (2003) lembra que os diversos corpos de água devem atender a usos múltiplos, conforme a classe a qual pertencem, decorrendo daí a necessidade da satisfação simultânea de diversos critérios de qualidade. Por exemplo, um rio utilizado apenas para diluição de despejos industriais e domésticos de uma cidade, pode ser utilizado por outra para abastecimento público.

A qualidade da água pode ser representada através de diversos parâmetros, que traduzem as principais características físicas, químicas e biológicas. Ao solicitar-se uma 
análise de água, é preciso selecionar os parâmetros a serem investigados nos exames e análises. Os principais usos, segundo (VON SPERLING, 2003) são:

- caracterização de águas para abastecimento águas superficiais (brutas e tratadas), águas subterrâneas (brutas e tratadas);

- caracterização de águas residuárias (brutas e tratadas);

- caracterização ambiental de corpos de água receptores (rios e lagos).

A resolução CONAMA n ${ }^{\circ} .357$, de 17 de março de 2005, dividiu as águas do território nacional em águas doces (salinidade < 0,5\%), salobras (salinidade entre 0,5\% e 30\%) e salinas (salinidade $>30 \%$ ). Em função dos usos previstos para as mesmas, foram criadas nove classes. A cada classe corresponde uma determinada qualidade a ser mantida.

Segundo o CONAMA n ${ }^{\circ} .357$, de 17/03/05, a classe 2 para águas doces é destinada:

a) ao abastecimento doméstico, após tratamento convencional;

b) à proteção das comunidades aquáticas;

c) à recreação de contato primário (natação, esqui aquático e mergulho);

d) à irrigação de hortaliças e plantas frutíferas;

e) à criação natural e/ou intensiva (aqüicultura) de espécies destinadas à alimentação humana.

Além dos requisitos que, de uma forma generalizada e conceitual, traduzem a qualidade desejada para a água, há a necessidade de se estabelecer também padrões de qualidade, embasados em um suporte legal. Da mesma forma que os requisitos, os padrões ocorrem em função do uso previsto para a água. Há três tipos de padrões que dizem respeito à qualidade da água (VON SPERLING, 2003):

- Padrões de lançamento no corpo receptor;

- Padrões de qualidade do corpo receptor;

- Padrões de qualidade para determinado uso imediato (ex. Padrão de Potabilidade). 
Os padrões de Potabilidade estão diretamente associados à qualidade da água fornecida ao consumidor. Tais padrões foram definidos na Portaria no. 518, de 25 de março de 2004, do Ministério da Saúde, que estabelece os procedimentos e responsabilidades relativas ao controle e vigilância da qualidade da água para consumo humano e seu padrão de potabilidade, e dá outras providências.

Apesar de todas as legislações em vigor, o grande crescimento populacional e o intenso desenvolvimento comercial, industrial e agrícola têm resultado na poluição e contaminação dos recursos hídricos superficiais e subterrâneos. Esta poluição ocorre por fertilizantes, carreados por água de drenagem, percolados de aterro sanitário, efluentes industriais e domésticos, entre outros.

Uma das tentativas de minimizar o impacto de despejos nos corpos hídricos naturais foi o desenvolvimento de uma técnica básica, que já tem um grande tempo de vida. Trata-se do processo de dissolver oxigênio de maneira forçada, conhecido como aeração ou reaeração. O oxigênio dissolvido na água é primordial para que haja vida no corpo hídrico. Os aspectos de qualidade e potabilidade estão intimamente ligados à oxigenação da água enquanto estiver no manancial. O oxigênio supre demandas químicas e biológicas para oxidar compostos nocivos, minimizando sua toxicidade.

A aeração se dá naturalmente pelos mecanismos de transporte devido aos movimentos do corpo hídrico. Entretanto, na regra, o processo natural tem baixa eficiência. A quantidade e a concentração dos efluentes requerem área de troca significativamente grande, incompatível com a área superficial dos corpos hídricos. Face aos problemas decorrentes da poluição, o homem precisa intervir no sentido de melhorar a eficiência, ou seja, aumentar a área de transporte de oxigênio dissolvido $(O D)$, através da aeração forçada. A maior quantidade de bolhas provê uma significante área de troca. Ademais, a intensa agitação devida ao deslocamento, decorrente do empuxo, aumenta ainda mais a eficiência da aeração forçada. 
Assim, a aeração forçada é largamente empregada no tratamento de efluentes líquidos. A questão do controle da aeração tem sido explorada, como maneira de reduzir custos operacionais (energia, principalmente) e de buscar maior eficiência operacional.

Existem várias formas de aumentar a área de contato oxigênio-água, desde a presença de obstáculos naturais para promover a turbulência do corpo de água (CIRPKA el al. 1993), passando pela agitação mecânica através de pás ou turbinas (NEDER, 1994), até a aeração por injeção de bolhas de ar no sistema através de difusores, chamada de aeração por bolhas (SHIAU, 1995). A utilização de um ou outro método depende não somente do espaço físico disponível mas, também, das características do resíduo a ser tratado e do orçamento disponível para implantação do sistema de tratamento. A TABELA 1 apresenta um resumo de alguns dos principais sistemas de aeração e a eficiência de transferência de cada um.

TABELA 1 - Dados de alguns sistemas de aeração. (SHIAU, 1995)

\begin{tabular}{|c|c|c|c|c|}
\hline $\begin{array}{l}\text { Sistema de } \\
\text { aeração }\end{array}$ & Descrição & Utilização & $\begin{array}{c}\text { Eficiência } \\
\text { de } \\
\text { transferên } \\
\text { cia de } 0_{2} \\
(\%)\end{array}$ & $\begin{array}{l}\text { Eficiência de } \\
\text { aeração } \\
\text { específica } \\
\left(\mathrm{kgO}_{2} / \mathrm{kWh}\right)\end{array}$ \\
\hline $\begin{array}{c}\text { Aerador } \\
\text { superficial } \\
\text { de baixa } \\
\text { velocidade }\end{array}$ & $\begin{array}{l}\text { Baixa velocidade, } \\
\text { grande diâmetro } \\
\text { do impulsor, base } \\
\text { fixa ou flutuante, } \\
\text { uso de engrenagem } \\
\text { redutora }\end{array}$ & $\begin{array}{c}\text { Todos os tamanhos } \\
\text { de sistemas } \\
\text { convencionais de } \\
\text { lodo ativado e } \\
\text { lagoas de aeração }\end{array}$ & -- & $1,2-4,6$ \\
\hline $\begin{array}{c}\text { Aerador } \\
\text { superficial } \\
\text { de alta } \\
\text { velocidade }\end{array}$ & $\begin{array}{l}\text { Alta velocidade, } \\
\text { pequeno diâmetro } \\
\text { do impulsor, } \\
\text { estrutura flutuante. }\end{array}$ & $\begin{array}{c}\text { Lagoas aeradas e } \\
\text { processos de lodo } \\
\text { ativado }\end{array}$ & -- & $1,2-3,5$ \\
\hline $\begin{array}{c}\text { Aerador de } \\
\text { escova }\end{array}$ & $\begin{array}{l}\text { Baixa velocidade, } \\
\text { uso de engrenagem } \\
\text { redutora, fornece } \\
\text { aeração e } \\
\text { circulação }\end{array}$ & $\begin{array}{c}\text { Vala oxidação } \\
\text { aplicado em lagoas } \\
\text { de aeração e } \\
\text { processo de lodo } \\
\text { ativado }\end{array}$ & -- & $\begin{array}{l}1,2-2,4 \\
\text { continuação }\end{array}$ \\
\hline
\end{tabular}




\begin{tabular}{|c|c|c|c|c|}
\hline $\begin{array}{c}\text { Aerador de } \\
\text { turbina }\end{array}$ & $\begin{array}{l}\text { Fornece violenta } \\
\text { agitação, ar } \\
\text { comprimido sobre } \\
\text { o anel dispersor } \\
\text { pode estar abaixo } \\
\text { do impulsor, } \\
\text { requer estrutura } \\
\text { fixa }\end{array}$ & $\begin{array}{c}\text { Processo } \\
\text { convencional de } \\
\text { lodo ativado }\end{array}$ & -- & $1,0-2,4$ \\
\hline $\begin{array}{l}\text { Aerador de } \\
\text { jato }\end{array}$ & $\begin{array}{l}\text { Ar comprimido e } \\
\text { líquido são } \\
\text { misturados e } \\
\text { descarregados } \\
\text { horizontalmente, a } \\
\text { elevação de pluma } \\
\text { de finas bolhas } \\
\text { produz mistura e } \\
\text { transferência de } \\
\text { oxigênio }\end{array}$ & $\begin{array}{l}\text { Processo de lodo } \\
\text { ativado, indústria } \\
\text { de fermentação }\end{array}$ & $10-25$ & $1,2-2,9$ \\
\hline $\begin{array}{l}\text { Difusor } \\
\text { (poroso) }\end{array}$ & $\begin{array}{l}\text { Produz pequenas } \\
\text { bolhas, feitos } \\
\text { placas ou tubos } \\
\text { cerâmicos, tecido e } \\
\text { plástico. }\end{array}$ & $\begin{array}{c}\text { Processos } \\
\text { convencionais de } \\
\text { lodo ativado em } \\
\text { grande escala. }\end{array}$ & $6-31$ & $0,9-3,0$ \\
\hline $\begin{array}{c}\text { Difusor } \\
\text { ( não- } \\
\text { poroso) }\end{array}$ & $\begin{array}{c}\text { Feito em estruturas } \\
\text { com orifícios, } \\
\text { válvulas, etc }\end{array}$ & $\begin{array}{l}\text { Todos os tipos de } \\
\text { processos de lodo } \\
\text { ativado }\end{array}$ & $4-13$ & $0,6-3,2$ \\
\hline
\end{tabular}

Diante do exposto, embora o processo de aeração seja profundamente pesquisado, salienta-se a necessidade de intensa busca de melhor eficiência de operação. O controle automático há muito tem contribuído em quase todos os processos da indústria de transformação química e física para atingir elevados graus de qualidade. A própria indústria de saneamento tem aplicado amplamente os recursos de automação. Enfim, qualidade de água é o tema desse trabalho, controle do processo de "limpeza" do corpo hídrico é o objetivo de contribuição. 


\section{OBJETIVOS}

A proposta de pesquisa tem cunho experimental e utiliza uma planta em escala laboratorial de um canal de aeração com os devidos instrumentos para aquisição de dados e controle da concentração de oxigênio dissolvido (O.D.).

São objetivos deste trabalho:

- Identificar um modelo linear para a transferência de oxigênio considerando as variáveis envolvidas no processo de aeração em operação contínua para fins de controle;

- $\quad$ Implementar uma rotina de monitoração e controle em tempo real; 


\section{REVISÃO BIBLIOGRÁFICA}

\subsection{Introdução}

Neste capítulo foi feita uma revisão das teorias que explicam a transferência de oxigênio da fase gasosa para a fase líquida e de alguns métodos para aeração. Também, procurou-se verificar a influência de parâmetros físicos e das condições de operação sobre o coeficiente de transferência de massa.

\subsection{Busca pela qualidade da água}

Os sistemas de controle da qualidade da água podem ser definidos como esforços direcionados a obter informações quantitativas a respeito das características físicas, químicas e biológicas da água, via amostragens estatísticas. O tipo de informação depende dos objetivos, que variam desde a detecção de violações aos padrões legais estabelecidos até determinações de tendências (SANDERS et al., 1987).

Determinar se a qualidade da água condiz com o uso pretendido parece ser a principal razão dos estudos realizados no ambiente aquático. Tradicional, o uso de monitoramento tem envolvido também a determinação de tendências, efeitos de contaminantes, atividades antrópicas, estimação de cargas poluidoras, etc. (MEYBECK et al., 1992). 


\subsection{Fundamentos da Transferência de Oxigênio}

O processo de reoxigenação da água, sob ação de borbulhamento sub-superficial de ar é bem conhecido. A recuperação do nível de saturação do $O D$, para a água em estado líquido e contínuo, misturado perfeitamente, pode ser descrita através do balanço de massa para o oxigênio dissolvido, como segue:

$$
\frac{d C}{d t}=K_{L} a\left(C_{S}-C\right)
$$

com a condição inicial:

$$
\mathrm{t}=\mathrm{O} \rightarrow \mathrm{C}=\mathrm{Co}
$$

soluciona-se a equação diferencial (1):

$$
C=C_{S}+\left(C_{0}-C_{S}\right) e^{-K L a t}
$$

Em que:

$d C / d t=$ taxa de transferência de oxigênio $-\mathrm{ML}^{-3} \mathrm{~T}^{-1}$;

$K_{L} a=$ coeficiente volumétrico global de transferência de oxigênio - $\mathrm{T}^{-1}$;

$C s=$ concentração de saturação de oxigênio dissolvido na água limpa $-\mathrm{ML}^{-3}$;

$C_{0}=$ concentração inicial de oxigênio dissolvido $-\mathrm{ML}^{-3}$;

$C=$ concentração de oxigênio dissolvido no seio líquido $-\mathrm{ML}^{-3}$; 
No caso de água residuária contendo nutrientes e população estável de microrganismos adequados ao seu tratamento, o processo desenvolve-se diferentemente.

A escolha dos equipamentos de aeração normalmente é determinada em relação à água limpa, em condições padrão de temperatura e pressão. A razão entre os valores dos parâmetros cinéticos e equilíbrio (termodinâmico) da água sob processo e da água limpa determina os valores dos parâmetros de correção. A seguir é apresentada a relação generalizada dos fatores de correção:

\section{Parâmetro de correção = parâmetro com água sob condições de processo} parâmetro com água Limpa

Para os sistemas aeróbios de tratamento de água residuárias, são conhecidos cinco principais parâmetros: $\alpha, \beta, \Theta, \Omega$ e $\tau . \quad \alpha$ e $\boldsymbol{\beta}$ são fatores influenciados pelas características da água sob condições de processo, sendo que $\boldsymbol{\alpha}$ corrige o coeficiente volumétrico global de transferência de massa $\left(K_{L} a\right)$ e $\boldsymbol{\beta}$ corrige a concentração de saturação $\left(C_{S}\right)$. $\boldsymbol{\Theta}$ e $\boldsymbol{\tau}$ corrigem os efeitos da temperatura para $K_{L} a$ e para $C_{S}$, respectivamente, e $\mathbf{\Omega}$ corrige o efeito da pressão para C $C_{S}$. A American Society of Civil Engineers - ASCE (1984) utiliza esses parâmetros com as mesmas nomenclaturas.

A TABELA 2 apresenta um resumo dos fatores de correção do coeficiente volumétrico de transferência de oxigênio e da concentração de saturação do oxigênio na água, tornando explícitos os parâmetros cinéticos envolvidos no processo, fornecendo base conceitual. 
TABELA 2 - Resumo dos fatores de correção do coeficiente volumétrico de transferência de oxigênio e da concentração de saturação do oxigênio na água.

\begin{tabular}{lll}
\hline $\begin{array}{l}\text { Fator de } \\
\text { Correção }\end{array}$ & Provoca sobre a(s) & Parâmetro Modificado \\
\hline$\alpha$ & Características da água sob condições & $\begin{array}{l}\text { Coeficiente de } \\
\text { Transferência }\left(K_{L} a\right)\end{array}$ \\
\hline$\beta$ & Característica da água sob condições & $\begin{array}{l}\text { Concentração de Saturação de } \\
\left(C_{S}\right)\end{array}$ \\
\hline$\Theta$ & processo & $\begin{array}{l}\text { Coeficiente de Transferência } \\
\left(K_{L} a\right)\end{array}$ \\
\hline$\tau$ & Temperatura & $\begin{array}{l}\text { Concentração de Saturação } \\
\left(C_{S}\right)\end{array}$ \\
\hline$\Omega$ & Temperatura & $\begin{array}{l}\text { Concentração de Saturação } \\
\left(C_{S}\right)\end{array}$ \\
\hline
\end{tabular}

FONTE: Aeration - A Wastewater Treatment Process - ASCE (1988)

Os parâmetros $\Theta, \tau$ e $\Omega$

Baseado na Lei de Arrhenius, $\Theta$, para condição de temperatura padrão $\left(20^{\circ} \mathrm{C}\right)$, é definido como:

$$
\Theta^{(t-20)}=\frac{K_{L} a_{T}}{K_{L} a_{20}}
$$

Em que:

$K_{L} a_{T}=$ coeficiente volumétrico de transferência de massa para água sob condições de processo $-\mathrm{T}^{-1}$

$K_{L} a_{20}=$ coeficiente volumétrico de transferência de massa para água limpa à temperatura de $20^{\circ} \mathrm{C}-\mathrm{T}^{-1}$

$\tau$ define a razão entre a concentração de saturação na temperatura da experimentação e a concentração de saturação padrão a $20^{\circ} \mathrm{C}$. 


$$
\tau=\frac{C_{S T}}{C_{S 20}}
$$

Em que:

$C_{S T}=$ concentração de saturação à temperatura $-\mathrm{ML}^{-3}$;

$C_{S 20}=$ concentração de saturação à temperatura de $20^{\circ} \mathrm{C}-\mathrm{ML}^{-3}$;

Não há consenso sobre a confiabilidade dos valores de $\tau$. Aconselha-se trabalhar com temperatura para a água limpa próxima à temperatura sob condições de processo (ASCE, 1988).

$$
\Omega=\frac{C_{S}\left(P_{b}\right)}{C_{S}\left(P_{S}\right)}=\frac{P_{b}+Y_{W T} d_{e}-P_{v T}}{P_{s}+Y_{W T}-P_{V T}}
$$

Em que:

$C_{S}\left(P_{b}\right)=$ concentração de saturação de $O D$ à pressão atmosférica nas condições experimentais $-\mathrm{ML}^{-3}$;

$C_{S}\left(P_{S}\right)=$ concentração de saturação de $O D$ à pressão padrão total de 1 atm com umidade relativa de $100 \%-\mathrm{ML}^{-3}$;

$P_{b}=$ pressão atmosférica nas condições experimentais $-\mathrm{ML}^{-1} \mathrm{~T}^{-2}$;

$P s=$ pressão padrão total de $1 \mathrm{~atm}$ com umidade relativa de $100 \%-\mathrm{ML}^{-1} \mathrm{~T}^{-2}$;

$Y_{w T}=$ densidade de massa da água à temperatura $\mathrm{T}-\mathrm{ML}^{-3}$;

$P_{v T}=$ pressão de vapor saturado à temperatura $\mathrm{T}$ da água $-\mathrm{ML}^{-1} \mathrm{~T}^{-2} ;$

$d_{e}=$ profundidade da saturação efetiva ao tempo infinito $\mathrm{L}^{2} \mathrm{~T}^{-1}$; 
Segundo a ASCE (1984), os valores de $\boldsymbol{\alpha}$ e $\boldsymbol{\beta}$ são necessários para descrever a influência das características das substâncias dissolvidas e sólidos suspensos nas águas residuárias, comparando à capacidade de transferência do equipamento de aeração para a água limpa. Geralmente, as medições de $\boldsymbol{\alpha}$ e $\boldsymbol{\beta}$ são realizadas quando as velocidades de transferência de campo podem ser comparadas com as velocidades de transferência padrão, para a água limpa.

A determinação dos parâmetros de correção é dada pela razão entre os parâmetros da água sob condições de processo e os mesmos parâmetros com a água limpa. Como se trata de uma razão considerando que as condições de temperatura e pressão em laboratório serão as mesmas para a água, não será necessário a utilização dos fatores $\Theta, \Omega$ e $\tau$, responsáveis pela padronização da temperatura e pressão.

Segundo a publicação de ASCE (1984), $\boldsymbol{\alpha}$ é definido como:

$$
\alpha=\underline{K}_{L} \underline{a} \underline{\text { na água sob condição de processo }}
$$

Vários fatores podem influenciar a determinação do parâmetro de correção $\alpha$, tais como: presença de surfactantes, turbulência, potência introduzida por unidade de volume, grau exigido de tratamento e distribuição das bolhas e outros.

$$
\begin{aligned}
& \boldsymbol{\beta} \text { pode ser definido como: } \\
& \beta=\frac{C s^{`} \text { na água sob condição de processo }}{C_{S} \text { na água Limpa }}
\end{aligned}
$$

Sendo que, $C_{S}{ }^{`}=$ concentração de equilíbrio na água sob condições de processo. Vários autores se utilizam desta forma de abordagem: CLARK el al. (1971), METCALF \& EDDY (1991); VIESSMAN \& HAMMER (1998). 
A determinação dos fatores de correção merece os devidos cuidados conceituais, necessários para uma resposta adequada dos sistemas de tratamento. Para tanto, é imprescindível a utilização das leis de conservação de energia e matéria.

A aplicação do balanço de massa e/ou energia, ferramenta básica para bom projeto na área de engenharia de processos, tem sido substituída por equações básicas, que muitas vezes geram respostas desastrosas para sistemas mal dimensionados.

Nos fenômenos ambientais relacionados ao gás oxigênio, componentes que fornecem oxigênio dissolvido ao seio líquido comunente são denominados fonte, e quando retiram oxigênio do seio líquido, sumidouro.

Uma abordagem clássica e geral para fenômenos envolvendo água residuária é discutida em CLARK et al. (1971), METCALF \& EDDY (1991), VIESSMAN \& HAMMER (1998). Tais autores apresentam o balanço de massa do $O D$, sujeito ao consumo microbiano como:

$$
\frac{d C}{d t}=K_{L} a\left(C_{s}-C\right)-r_{m}
$$

Em que:

$d C / d t_{-}=$velocidade de transferência do oxigênio, $\mathrm{ML}^{-3} \mathrm{~T}^{-1}$;

$K_{L} a=$ coeficiente volumétrico global de transferência de oxigênio, $\mathrm{T}^{-1}$;

$r_{m}=$ velocidade da reação microbiana - as dimensões dependem da ordem da reação

A segunda parcela, do segundo membro da Equação ( 8 ), é a parcela que representa o consumo microbiano. Nesse caso, o principal responsável pelo consumo de $O D$ é a população microbiana aeróbia. 
A presença de alguns tipos de substâncias na água, como surfactantes nome dado composto que reduza a tensão superficial de uma solução, como os detergentes e emulsificantes; tensoativo e hidrocarbonetos, pode alterar a estrutura da interface fluidofluido, produzindo mudanças significativas nos valores do coeficiente volumétrico de transferência. A presença desses compostos pode, efetivamente, modificar a estrutura física da interface, refletindo em alterações nos valores dos parâmetros.

Para o caso em que há presença de fontes e/ou sumidouros de $O D$ no sistema, $K_{L} a$ não se altera. O que ocorre é a participação combinada do coeficiente volumétrico de transferência de oxigênio, juntamente com os coeficientes responsáveis pelo fornecimento ou retirada de oxigênio. Como exemplos de coeficientes de retirada de $O D$ podem ser citados os coeficientes de desoxigenação, que quantificam:

- o consumo microbiano do $O D$,

- oxidantes químicos que consomem o $O D$ do seio líquido. Por exemplo, utilizamos nesse trabalho sulfito de sódio para consumir o oxigênio até níveis préestabelecidos,

- o processo de "stripping" - dessorção, que retira o $O D$ do sistema por interações físicas.

Neste caso $K_{L} a^{`}$ não representa o coeficiente volumétrico de transferência $\left(K_{L} a\right)$, modificado por mudanças na estrutura da interface, mas sim $K_{L} a$ combinado com outros coeficientes gerados pelas fontes (coeficientes de reoxigenação) e/ou sumidouros (coeficientes de desoxigenação).

Portanto, quando há a presença de fontes e/ou sumidouros de $O D, K_{L} a ` e ́$ resultado da combinação de $K_{L} a$ com outros coeficientes. Quando há a presença de substâncias que possam alterar a estrutura na interface fluido-fluido, $K_{L} a^{`}$ é resultado da modificação efetiva de $K_{L} a$, ou seja, $K_{L} a^{`}$ é o próprio coeficiente volumétrico. 
Alguns estudos de caso sobre a influência de substâncias que modificam a estrutura da interface gás-líquido estão resumidos abaixo:

- Zieminski et al. (1967), analisaram o comportamento de bolhas de ar em solução aquosa diluída de alguns compostos e descobriram que os valores do coeficiente volumétrico de transferência de massa aumentaram na presença do acido di-carboxílico e do álcool alifático.

- Zieminski \& Lessard (1969), estudaram o efeito de aditivos químicos no desempenho de um dispositivo de contato entre ar e água e atribuíram o aumento da velocidade de transferência de oxigênio ao aumento da área superficial de contato.

- Koide et al. (1976) analisaram a transferência de massa de bolhas isoladas em soluções aquosas contendo surfactantes e verificaram que o valor do coeficiente volumétrico de transferência da massa diminui na presença de tais compostos.

- Leu et al. (1998), reportaram os efeitos de surfactantes e de sólidos suspensos sobre a velocidade de transferência de oxigênio e perceberam que os valores do coeficiente volumétrico de transferência de oxigênio diminuíam com o mínimo aumento das concentrações de surfactantes e de sólidos suspensos.

No que se refere ao controle do processo de aeração, foram encontrados alguns trabalhos informativos, a maioria com aplicação em tratamento de efluentes. Descrito em 3.5.2.

\subsubsection{Teorias sobre transferência de oxigênio}

A quantidade de oxigênio transferida do ar para a água por unidade de tempo é determinada pela solubilidade do oxigênio na água, pela passagem através da interface ar/água e pela difusão do oxigênio na água. Estes processos são influenciados pela 
interdependência entre diversos fatores, sendo estes: temperatura, concentração de saturação de oxigênio da água, concentração instantânea do oxigênio na água, turbulência, dimensões e geometria do tanque e do sistema de aeração (GASSEN, 1977)

Um dos principais parâmetros necessários ao dimensionamento de uma unidade de tratamento de águas residuárias é o coeficiente global de transferência de oxigênio entre o ar e a água, chamado $K_{L}$ a. Esse parâmetro é uma medida da velocidade com que o sistema de aeração transfere oxigênio para a água e serve como referência para a eficiência do processo de aeração. Independente do tipo de sistema de aeração utilizado, é possível desenvolver modelos teóricos ou semi-empíricos que expliquem o mecanismo de transferência entre as fases líquida e gasosa.

Existem 3 teorias básicas que procuram explicar a transferência de massa entre as fases gasosa e líquida: teoria dos dois filmes, teoria da penetração e teoria da renovação superficial discutida em SCHROEDER (1977), BARBOSA (1989), SHIAU (1995). É apresentada a seguir uma descrição resumida de cada uma das teorias.

\subsubsection{Teoria dos dois filmes}

Proposta por Lewis e Whitman (1924), a teoria dos dois filmes é a mais antiga e a mais simples de todas, propondo que na superfície da interface haja a formação de um filme líquido e outro gasoso que oferecem resistências à passagem do gás da fase gasosa para a fase líquida. As principais hipóteses para o desenvolvimento dessa teoria são:

- fluxo massa do volume ocorre ao longo de ambos os lados da interface gás-líquido; - condições de regime permanente;

- estabelecimento instantâneo das condições de equilíbrio entre as fases líquida e gasosa na interface. 
A FIGURA 1 mostra a transferência de massa entre as fases proposta pela teoria dos dois filmes, a qual é dividida em três etapas:

- Transferência de massa do meio gasoso para a superfície interfacial;

- Transferência através da interface por difusão molecular;

- Transferência da superfície interfacial para o meio líquido.

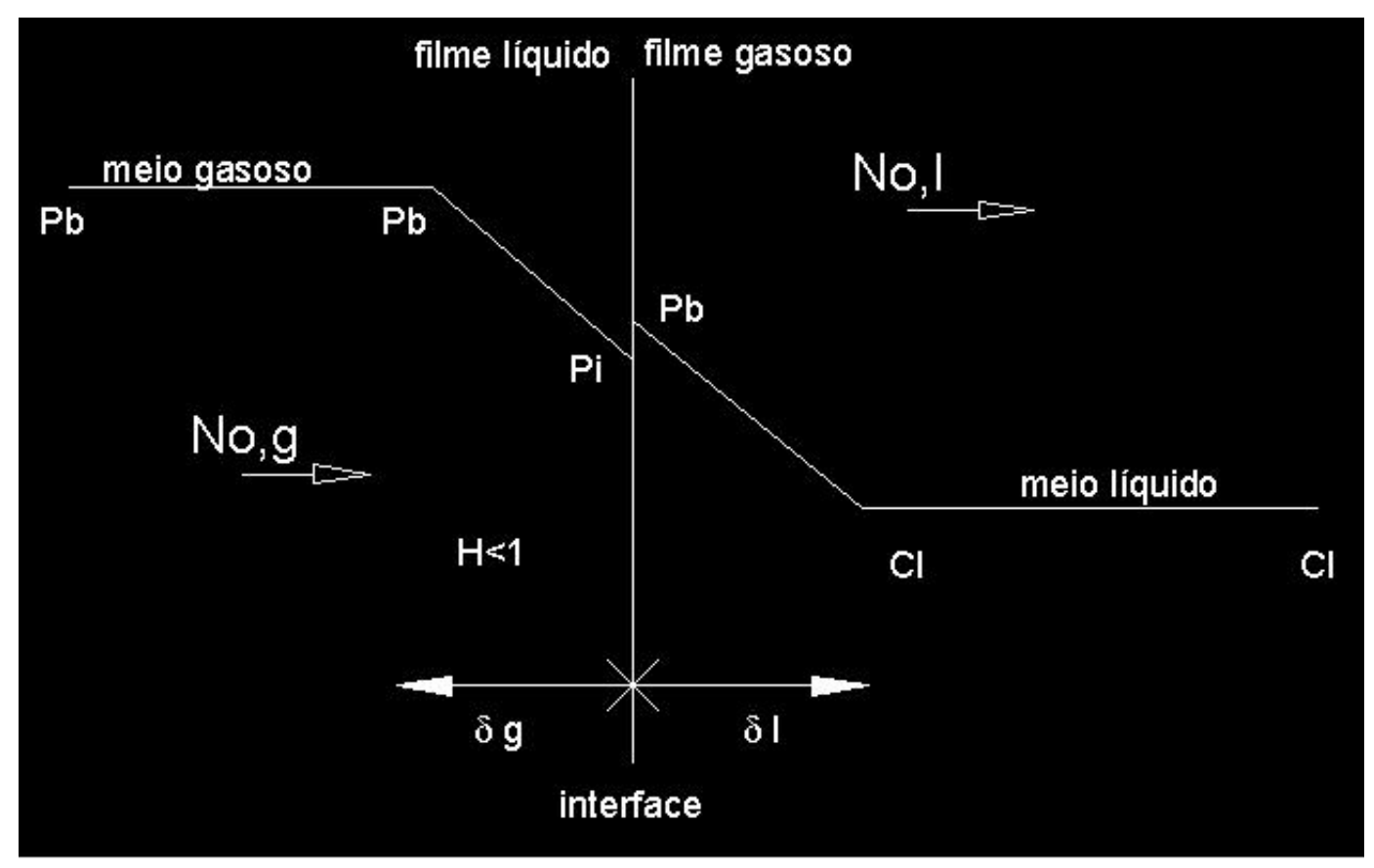

FIGURA 1 - Diagrama esquemático da transferência gás-líquido proposta pela teoria dos dois filmes. Fonte modificada: Levenspiel (1999).

Quando em regime, o fluxo de oxigênio através do filme gasoso $\mathrm{N}_{\mathrm{O}, \mathrm{g}}$ deve ser o mesmo que o fluxo através do filme líquido, $\mathrm{N}_{\mathrm{O}, \mathrm{I}} \mathrm{O}$ gradiente de concentração, ou de pressão parcial é causado pelo consumo químico ou bioquímico do oxigênio contido na fase líquida.Assim:

$$
N_{O, g}=K g \cdot\left(P_{b}-P_{i}\right)
$$




$$
N_{O, l}=K_{L} \cdot\left(C_{i}-C_{L}\right)
$$

Onde:

$P_{b}=$ pressão parcial no meio gasoso, $\mathrm{ML}^{-1} \mathrm{~T}^{-2}$;

$P_{i}=$ pressão parcial na interface, $\mathrm{ML}^{-1} \mathrm{~T}^{-2}$;

$C i=$ concentração de oxigênio na interface líquida, $\mathrm{ML}^{-3}$;

$C_{L=}$ concentração de oxigênio no meio líquido, $\mathrm{ML}^{-3}$

$\mathrm{K}_{\mathrm{l}}$ e $\mathrm{K}_{\mathrm{g}}=$ coeficientes de transferência de massa para os filmes líquido e gasoso, e correspondem idealmente à $\mathrm{D} / \delta$, onde $\mathrm{D}$ é a difusividade molecular, $\mathrm{L} \mathrm{T}^{-1}$;

$\delta=$ espessura do filme

Pela lei de Henry, é sabido que a concentração na interface Ci está em equilíbrio com a pressão parcial do gás, Pi. Assim:

$$
P_{i}=H . C_{i}
$$

onde:

$H=$ constante de Henry.

Considerando $\mathrm{C}^{*} \mathrm{e} \mathrm{P}^{*}$, que correspondem às concentrações de equilíbrio que deveriam estar associadas com a pressão parcial no meio gasoso, $P_{b}$, e a concentração $C_{L}$, respectivamente, pode-se obter as seguintes expressões:

$$
\begin{aligned}
& P_{b}-P_{i}=H .\left(C^{*}-C i\right) \\
& P_{i}-P^{*}=H .\left(C_{i}-C_{L}\right)
\end{aligned}
$$


Substituindo essas relações nas Equações ( 9 ) e ( 10 ) e eliminando as concentrações na interface, tem-se:

$$
N_{O}=K_{L} \cdot\left(C^{*}-C_{L}\right)
$$

Onde:

$$
K_{L}=\frac{k_{g} \cdot k_{L} \cdot H}{k_{l}+k_{g} \cdot H}
$$

Em que:

$K_{L}=$ coeficiente de transferência de massa global, $\mathrm{L} \mathrm{T}^{-1}$;

$k_{g}=$ velocidade de transferência de massa no filme gasoso viscoso, $\mathrm{L} \mathrm{T}^{-1}$;

$k_{l}=$ velocidade de transferência de massa no filme líquido viscoso, $\mathrm{L} \mathrm{T}^{-1}$;

$H=$ constante de Henry, atm $\mathrm{m}^{-3} \mathrm{~mol}^{-1}$;

$K_{L}$ é o coeficiente de transferência de massa global e corresponde à composição entre os coeficientes individuais de transferência de massa em cada fase. Expressão similar à Equação (15) pode ser desenvolvida levando-se em conta a fase gasosa.

A principal vantagem da Equação (14) é que ela apresenta grandezas mensuráveis, como a concentração de oxigênio na fase líquida e a concentração de saturação. Ao contrário, grandezas como $P i$ e $C i$, apresentadas nas Equações ( 9 ) e (10) não podem ser determinadas experimentalmente. No caso da transferência de oxigênio, a resistência do filme líquido, $1 / \mathrm{k}_{1}$ é consideravelmente maior que a resistência no filme gasoso, $1 / \mathrm{k}_{\mathrm{g}}$. Desse modo, o filme líquido normalmente controla a taxa de transferência de oxigênio através da interface. 
A principal desvantagem do modelo de Lewis e Whitman é que dificilmente ocorre um escoamento tranqüilo para apresentar uma camada verdadeiramente laminar na interface gáslíquido. Contudo, por sua simplicidade esse modelo continua sendo utilizado como base de outros modelos.

\subsubsection{Teoria da penetração}

Higbie (1935), foi quem primeiro postulou a teoria da penetração. Ele considerou o sistema mostrado na FIGURA (1) para um estado transiente e para condições do filme líquido ser a etapa controladora do processo. Supondo que nenhuma reação química ocorra, tem-se:

$$
\frac{\partial C}{\partial t}=D \cdot \frac{\partial^{2} C}{\partial z^{2}}
$$

Onde:

$D=$ difusividade molecular do oxigênio na água, $\mathrm{ML}^{-2}$;

$\mathrm{z}=$ profundidade a partir da superfície - distância à interface, $\mathrm{L}$;

$\mathrm{C}=$ parâmetros independentes do tempo.

A condição inicial e de contorno para a Equação (16) são:

$$
\begin{array}{lll}
\mathrm{C}=\mathrm{C}_{\mathrm{L}} & \text { para } & \mathrm{t}=0 ; \\
\mathrm{C}=\mathrm{C}_{\mathrm{S}} & \text { em } & \mathrm{y}=0, \text { para } \mathrm{t}>0 ; \\
\mathrm{C}=\mathrm{C}_{\mathrm{L}} & \text { quando } & \mathrm{y} \rightarrow \infty .
\end{array}
$$


Higbie (1935) estava interessado nas etapas iniciais da transferência de massa entre as fases em que para uma camada infinitamente extensa fossem aplicadas as seguintes condições:

$\begin{array}{lll}\mathrm{t}=0 & \mathrm{z}>0 & \mathrm{C}=\mathrm{C}_{\mathrm{L}} \\ \mathrm{t}>0 & \mathrm{z}=0 & \mathrm{C}=\mathrm{C}^{*} \\ \mathrm{t}>0 & \mathrm{z} \rightarrow \infty & \mathrm{C}=\mathrm{C}_{\mathrm{L}}\end{array}$

Resolvendo a Equação (16) por mudança de variáveis, $C^{\prime}=C-C_{L}$, o fluxo na interface pode se calculado como:

$$
N_{O}=-\left(C *-C_{L}\right) \cdot \sqrt{\frac{D}{\pi \cdot t_{c}}}
$$

Em que:

$\mathrm{C}=$ concentração instantânea, $\mathrm{ML}^{-3}$;

$\mathrm{C}_{\mathrm{L}}=$ concentração líquido, $\mathrm{ML}^{-3}$;

$\mathrm{D}=$ difusão tubulenta, $\mathrm{m}^{2} / \mathrm{s}$;

$\mathrm{t}_{\mathrm{c}}=$ tempo retenção celular, $\mathrm{T}$.

A partir da Equação (17) pode ser interpretado que quanto mais curto for o tempo de contato, maior será a taxa de transferência de oxigênio. Na aeração por bolhas, por exemplo, diminuir o tempo de contato significa aumentar a mistura (turbulência) na interface gáslíquido. Na aeração superficial, também significa aumentar a turbulência. Na prática, essa melhora no processo de transferência está relacionada às mudanças na geometria do sistema. 


\subsubsection{Teoria da renovação superficial}

Shiau (1995) estendeu a teoria da penetração considerando o caso em que porções do líquido estariam na interface em períodos de tempo finitos. Por causa da turbulência, o tempo de contato dos elementos líquidos estaria aleatoriamente distribuído. Esse conceito é conhecido como teoria da renovação superficial aleatória. Supôs que havia uma taxa de produção de superfície nova por unidade de superfície disponível, e essa taxa era independente da idade do elemento líquido em questão. Ele definiu uma área superficial, $A(t)$. $\Delta t$, com idade entre $t$ e $t+\Delta t$, e fez um balanço de área:

$$
A(t) . \Delta t=A(t-\Delta t) . \Delta t-[A(t-\Delta t) . \Delta t] . r_{S} \cdot \Delta t
$$

Onde:

$[A(t-\Delta t) \cdot \Delta t] \cdot r_{S} \cdot \Delta t=$ é a quantidade de área renovada no tempo $\Delta t$. Essa expressão pode ser rearranjada em termos diferenciais, aproximando-se $\Delta t$.de zero:

$$
\frac{\mathrm{dA}(\mathrm{t})}{\mathrm{dt}}=-r_{S} \cdot \mathrm{A}(\mathrm{t})
$$

Em que:

A integração da Equação (19) fornece:

$$
A(t)=\text { Constante } \cdot \exp \left[-\mathrm{r}_{\mathrm{S}} . \mathrm{t}\right]
$$

Outros modelos para a transferência de massa em superfícies livres, incluindo parâmetros de difusividade turbulenta, ou teoria cinética, podem ser encontrados na revisão 
feita por Bennett e Rathbun (1972), segundo SHIAU (1995). Todos esse modelos, no entanto, apresentam algum termo de difícil verificação experimental, o que muitas vezes acaba por torná-los úteis apenas para efeito comparativo a outros modelos ou para tratamento teórico do

problema. Bennett e Rathbun também apresentaram alguns modelos semi-empíricos e equações empíricas para tratamento do fenômeno de transferência de massa entre fases líquida e gasosa. A utilidade de tais modelos está principalmente na possibilidade de predição do coeficiente de transferência de oxigênio, $K_{L}$.

Em seu trabalho, SHIAU (1995), escolheu o modelo de renovação superficial para expressar a transferência de massa entre as fases:

$$
M=K_{L} \cdot A \cdot\left(C_{S}-C_{L}\right)
$$

Onde:

$M=$ é a massa de oxigênio transferido por unidade de tempo; $\mathrm{Mmol}^{-1}$;

$K_{L}=$ é o coeficiente de transferência baseado no filme líquido (relacionado à taxa de renovação superficial), $\mathrm{L} \mathrm{T}^{-1}$;

$A=$ é a área interfacial para a transferência; $\mathrm{L}^{2}$

$C_{S}=$ é a concentração de saturação do oxigênio na interface, $\mathrm{ML}^{-3}$;

$C_{L}=$ é a concentração de oxigênio no líquido, $\mathrm{ML}^{-3}$;

\subsection{Fatores que afetam a transferência de oxigênio}

Os fatores que afetam a transferência do oxigênio dependem do tipo de sistema de aeração. Em relação à aeração por ar difuso, é importante destacar as influência: da temperatura, presença de componentes orgânicos, turbulência, área de transferência e outros 
sobre os parâmetros de equacionamento, tais como a concentração de saturação e o coeficiente global de transferência.

\subsubsection{Concentração de saturação}

Como explica Welty (1984), o valor da saturação do oxigênio na água está relacionado à pressão parcial do oxigênio na fase gasosa através da lei de Henry:

$$
\mathrm{P}^{*}=\mathrm{H} \cdot \mathrm{C}_{\mathrm{S}}
$$

Onde:

$C_{S}=$ é a concentração de saturação do oxigênio, $\mathrm{ML}^{-3}$; $H=$ é a constante de Henry;

$P^{*}=$ é a pressão parcial do oxigênio (para o $\mathrm{ar}=0,209 \mathrm{x}$ pressão total), $\mathrm{ML}^{-1} \mathrm{~T}^{-2}$;

A concentração de saturação sofre influência da temperatura, salinidade, altitude e presença de outros constituintes químicos. O aumento na latitude causa diminuição na pressão atmosférica e, consequentemente, na pressão parcial do oxigênio, diminuindo assim a concentração de saturação em equilíbrio. Em relação à presença de sólidos não existe uma relação muito confiável com a concentração de saturação, dependendo muito das características dos resíduos. Na prática, estima-se um fator de correção que deve permanecer aproximadamente constante, mantendo-se outros fatores fixos. 


\subsubsection{Coeficiente global de transferência de oxigênio, $K_{L} a$}

O coeficiente global de transferência, $K_{L} a$, é uma combinação entre o coeficiente de transferência de massa baseado no filme líquido e a área específica de transferência. Em relação ao primeiro, Higbie (1935) e Dankwertz (1951), propuseram que $K_{L}$ seria proporcional à raiz quadrada da difusividade e dependeria da tensão e características moleculares que prevaleceriam na superfície de troca.

A área específica de troca, por sua vez, irá depender do grau de turbulência no sistema, promovendo o contato gás-líquido. Indiretamente, esse parâmetro dependerá do tipo de sistema de aeração envolvido. Por exemplo, é sabido que o sistema de aeração por bolhas é um dos que apresentam maior área específica de troca, otimizando o processo de transferência.

Em relação à temperatura, o coeficiente de transferência seria influenciado pela seguinte expressão, mostrada por SHIAU (1985).

$$
f c=\frac{K_{L} a_{(T)}}{K_{L} a_{(20)}}=\theta^{(T-20)}
$$

Onde:

$K_{L} a_{(T)}=$ coeficiente de transferência na temperatura de operação, $\mathrm{T}^{-1}$;

$K_{L} a_{(20)}=$ coeficiente de transferência a $20^{\circ} \mathrm{C} \mathrm{T}^{-1}$;

$\theta=$ constante que varia de sistema para sistema.

Barbosa (1989) apresentou um resumo dos valores de $\theta$ segundo diversos autores. Esses valores são mostrados na TABELA 3. 
A explicação, apud Barbosa (1989), seria o fato de temperatura afetar a velocidade das moléculas de oxigênio na água e no ar acima da superfície livre. Em conseqüência, a uma elevação de temperatura deve corresponder um aumento na taxa de difusão molecular do soluto gasoso no filme líquido superficial. Outras vezes, esse aumento é justificado pelo fato da difusividade molecular depender das propriedades física da água, ou seja, o aumento da temperatura, além de conduzir a um aumento da energia vibracional das moléculas na interface gás-líquido.

TABELA 3 - Coeficiente para correção de $K_{L} a$ com a temperatura.( BARBOSA, 1989).

\section{$\Theta \quad$ Pesquisador / Ano / Sistema de operação}

\begin{tabular}{ll}
\hline 1,0159 & Streeter e Phelps / 1926 / Ajuste dos dados para reaeração do rio Ohio. \\
\hline 1,047 & Sreeter et al. / 1936 / Canal experimental. \\
\hline 1,0241 & Elmore e West / 1961 / Agitação com superfície livre não quebrada. \\
\hline 1,0226 & Elmore e West / 1961 / Agitação com formação de vórtices. \\
\hline 1,024 & Churchill et al. / 1962 / Agitação, com superfície livre não quebrada. \\
\hline 1,022 & Tsivoglou / 1967 / Agitação, com superfície livre não quebrada.
\end{tabular}

Quando oxigênio é fornecido a sistemas de tratamento de águas residuárias, é necessário definir um fator de correção que relacione a transferência de oxigênio à natureza do resíduo. Usando como referência a transferência de oxigênio na água limpa, o parâmetro $\alpha$ serve como fator de correção como se segue:

$$
\alpha=\frac{K_{L} a(\text { água residuária })}{K_{L} a(\text { água })}
$$


Segundo SHIAU, 1995 existem muitas variáveis que afetam a magnitude de $\alpha$, incluindo:

- temperatura do resíduo;

- natureza dos constituintes orgânicos e minerais dissolvidos;

- características do equipamento de aeração;

- intensidade da turbulência afetando a taxa de renovação superficial;

- profundidade e geometria do tanque de aeração.

Shiau (1995), afirma que, até o momento, não existe uma teoria que explique razoavelmente o impacto de materiais orgânicos sobre a transferência de oxigênio. De qualquer modo, propõe uma equação que expressa a interação dos parâmetros das águas residuárias com aqueles da "água pura":

$$
\frac{d\left(\beta . C_{S}-C_{t}\right)}{d t}=\alpha . K_{L} a\left(\beta . C_{S}-C_{t}\right)+\gamma
$$

Onde:

$\gamma=$ é a taxa de consumo de oxigênio dissolvido pelo sistema;

$C_{S}=$ é a concentração de saturação do oxigênio dissolvido para a água pura, $\mathrm{ML}^{-3}$;

$C_{t}=$ é a concentração de oxigênio dissolvido no resíduo, em função do tempo, $\mathrm{ML}^{-3}$;

$K_{L} a=$ é o coeficiente de transferência global de oxigênio na água pura, $\mathrm{T}^{-1}$.

$\beta=$ parâmetro de correção da concentração de saturação de oxigênio dissolvido

O produto $\left(\alpha . K_{L} a\right)$ representa o coeficiente real de transferência de oxigênio para a água residuária em uma temperatura. A Equação (23) pode então ser usada para calcular o coeficiente de transferência à $20^{\circ} \mathrm{C}$. 


\subsection{Métodos de Aeração}

Nos processos biológicos de tratamento de águas residuárias, a transferência de oxigênio é feita em duas etapas conforme mostrado na FIGURA 1. Primeiro o oxigênio é transferido para a solução e, a seguir ocorre sua utilização pelos microrganismos aglomerados em suspensão, formando flocos. Em estudo realizado pelo Departamento de Mecânica dos Fluidos da Universidade de Erlangen, Alemanha, os testes foram feitos em reator tipo batelada, utilizando-se água de abastecimento e substrato sintético, para simular esgoto doméstico. A capacidade e eficiência de oxigenação foram determinadas segundo as condições padrão da Alemanha, regidas pela ATV; o equipamento alcançou valores de eficiência de oxigenação entre 1,0 e $3,0 \mathrm{~kg} 0_{2} / \mathrm{kWh}$, indicado para sistemas de tratamento em nível secundário e terciário. (ZÄHRINGER, 1992).

O estudo da transferência de gases em interfaces ar-água (caso particular de interfaces gás-líquido), tanto em escoamentos naturais (rios, córregos, lagos etc) como nos artificiais (tanques, canais etc) não é recente. Desde as primeiras décadas deste século os pesquisadores têm procurado formas de convenientemente quantificar o fenômeno que, apesar dos esforços, tem se mostrado de difícil tratamento quanto às quantificações definitivas, uma vez que as dificuldades estão associadas ao fato de os sistemas estudados estarem sujeitos à agitação turbulenta.

Neste tipo de estudo os pesquisadores concentram-se principalmente na "previsão" do coeficiente de transferência, representado por $\boldsymbol{K}$ (coeficiente de transferência de massa, $\mathrm{s}^{-1}$ ), para o qual ainda não se possui equacionamento geral definitivo, quando se consideram parâmetros de escoamento facilmente mensuráveis e parâmetros físico-químicos comumente utilizados para quantificar processos de transferência na interface ar-água. (SHULZ, 1989) 
De acordo com Barbosa (1997), Rathbun el al. (1978) e outros, os coeficientes de reaeração usados em modelos de previsão geralmente são estimados a partir de equações de natureza teórica, empírica ou semi-empírica. Por um lado os modelos teóricos se apresentam inadequados por conterem parâmetros não facilmente relacionados ao escoamento ou características hidráulicas desse escoamento. Por outro lado, tornam-se capazes de prever. $\boldsymbol{K}$ satisfatoriamente, somente quando os referidos parâmetros são semelhantes àqueles em que as equações se basearam, tais como velocidade, profundidade, declividade média, principalmente no que se refere aos escoamentos naturais.

\subsubsection{Equipamentos para processos de aeração}

Historicamente, a injeção de ar em sistemas de tratamento tem sido utilizada desde o século passado. Segundo Peot (1969), água residuária e cal foram misturados pelo ar em 1893, em Wooster, Massachusetts. Portanto, há muito tempo Archbutt e Dealey já aeravam esgoto, em 1892, em Heapley, Inglaterra, para obter oxidação. Clark (1971) introduziu ar em um tanque em Lawrence, na estação experimental de Massachusetts, em 1912, colocando um tubo perfurado no fundo de seu tanque para dispersar o ar em pequenas bolhas. Mais tarde o tubo perfurado foi recoberto com uma rede fina a fim de produzir bolhas de tamanhos reduzidos. Outros pesquisadores tentaram vários materiais sobre os tubos perfurados, tais como tecidos, feltros, lonas, telas e de arame e metais perfurados, de modo a conseguirem bolhas pequenas. Nordell ( PEOT, 1969) chegou a testar difusores feitos de madeira, cortados em secção transversal para obter bolhas pequenas e promover fluxo circular em seu tanque de aeração do tipo chaminé.

$\mathrm{Na}$ estação experimental da Ilha de Jones, em Milwalkee, Wisconsin, Dalton e Copeland, em 1925, (PEOT, 1969), trabalhando com lodo ativado, pesquisaram o método de 
purificação de resíduos e fizeram extensos estudos sobre meios difusores, tamanho de bolha de ar, efetividade de bolhas pequenas em relação à profundidade do tanque; os autores desenvolveram princípios de operação contínua e resolveram o problema de disposição dos resíduos produzindo fertilizantes de milorganita.

Segundo Metcalf e Eddy (1991), os difusores mais comumente usados em sistemas de aeração são projetados para produzir bolhas pequenas, médias ou relativamente grandes. Eles estão descritos na TABELA 4 e mostrados esquematicamente na FIGURA 2.

Placas difusoras são instaladas em suportes de concreto ou alumínio, contendo seis ou mais placas dispostas em desnível ou no fundo do tanque de aeração. Grupos de suportes são conectados à tubulação fornecedora de ar, em intervalos ao longo do comprimento do tanque e cada grupo é controlado por uma válvula.

Tubos difusores são parafusados a tubos de distribuição de ar, que podem ser dispostos ao longo do comprimento do tanque, ou dispostos em pequenos grupos, com tubos móveis, para facilitar a limpeza.

O domo difusor mostrado na FIGURA 2 b consiste em uma peça porosa de 17,8 centímetros de diâmetro, construído em material cerâmico. O domo difusor é projetado para assegurar permeabilidade uniforme e produzir bolhas de diâmetro de cerca de $2 \mathrm{~mm}$. O movimento ascendente das bolhas evita o depósito de sedimentos no fundo do tanque e garante uma suave mistura do líquido. Os domos normalmente são montados em uma rede de tubos de PVC dispostos ao longo do tanque. O espaçamento entre os domos e entre as fileiras varia de 30 a 76 centímetros, dependendo das condições do resíduo tratado.

A história da utilização de sistemas de difusão indica ampla durabilidade, mas com ocorrência de diminuição no desempenho com o tempo de operação, principalmente devido ao entupimento dos poros, tanto do lado gasoso quanto do lado líquido, causando aumento na queda de pressão do sistema. Com difusores porosos, é essencial que o ar fornecido seja limpo 
e livre de partículas de pó, que poderiam causar o entupimento dos poros do difusor. Filtros de ar, frequentemente consistindo barreiras físicas, são colocados na entrada dos sopradores. Filtros de manga e precipitadores eletrostáticos também têm sido utilizados.

TABELA 4 - Descrição de alguns equipamentos para aeração por ar difuso.(METCALF \& EDDY, 1979)

\begin{tabular}{|c|c|c|c|}
\hline $\begin{array}{c}\text { Tamanho da } \\
\text { bolha } \\
\text { produzida } \\
\end{array}$ & $\begin{array}{l}\text { Eficiência de } \\
\text { transferência }\end{array}$ & Descrição & Figura \\
\hline \multirow[t]{6}{*}{ Pequenas } & Alta & 1. Grãos de oxido de alumínio & -- \\
\hline & & cristalino ceramicamente ligados & $2 a, b$ \\
\hline & & 2. Grãos de sílica pura ligados por & -- \\
\hline & & silicatos vítreos & $2 \mathrm{a}$ \\
\hline & & 3. Grãos de sílica pura ligados por & -- \\
\hline & & resina & $2 \mathrm{a}$ \\
\hline \multirow[t]{4}{*}{ Média } & Média & 1. Tubos difusores de plástico & \\
\hline & & empacotado & $2 \mathrm{c}$ \\
\hline & & 2. Difusores de manga, feita de tecido & \\
\hline & & trançado & $2 d$ \\
\hline \multirow[t]{6}{*}{ Grandes } & Baixa & 1. Equipamentos de vários orifícios. & $2 \mathrm{e}$ \\
\hline & & 2. $\mathrm{O}$ ar escapa pela periferia do disco & \\
\hline & & rígido ou flexível que é deslocado & -- \\
\hline & & quando a pressão do ar excede a & -- \\
\hline & & carga sobre o disco & $2 \mathrm{f}$ \\
\hline & & 3. Injetores de orifícios de ranhuras & $2 \mathrm{f}$ \\
\hline
\end{tabular}




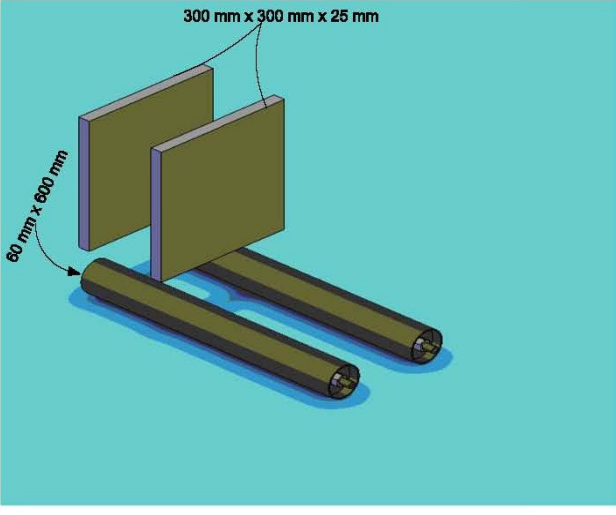

( a )

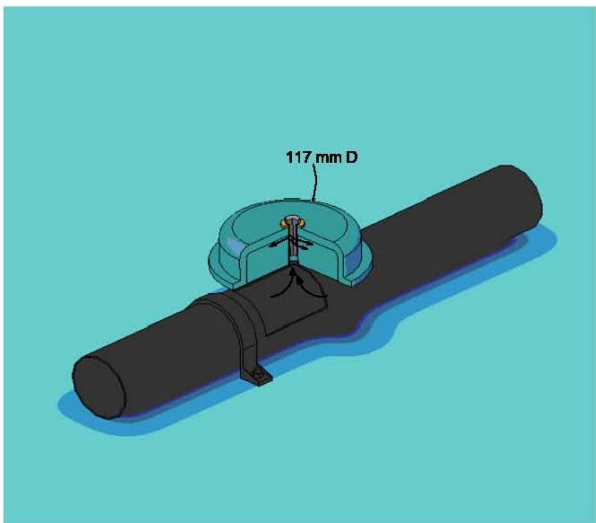

(b)

(a) Difusores de placas e tubos (Ferro corp.); (b) Domo difusor (Norton Co.);

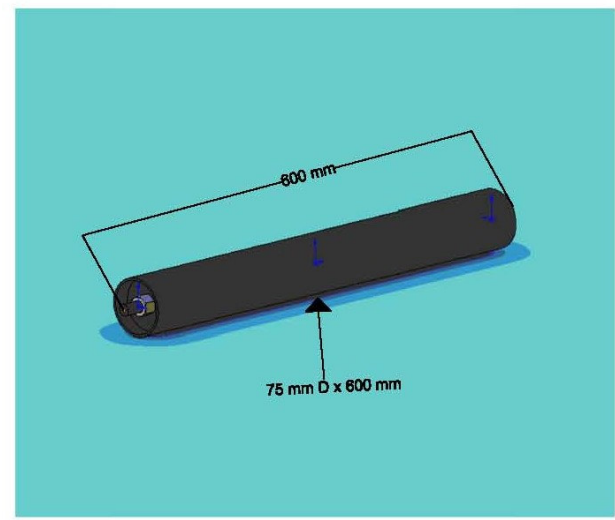

(C)

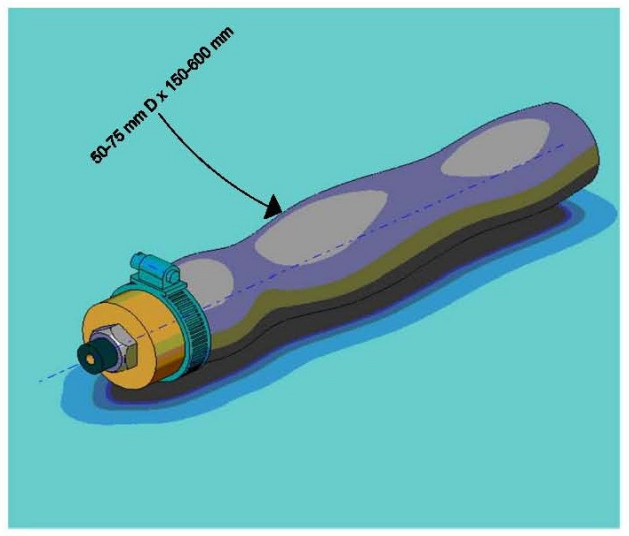

(d)

(c) Difusor de precisão de fibra de saran empacotada (FMC, Chicago Pump.);

(d) Flexufuser (FMC, Chicago Pump.);

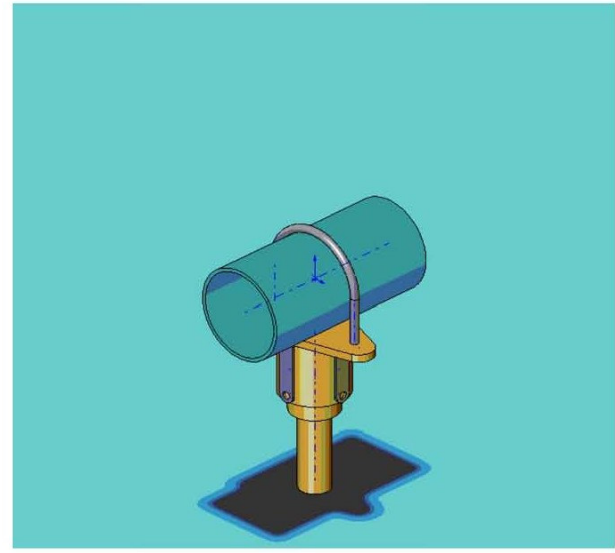

(e)

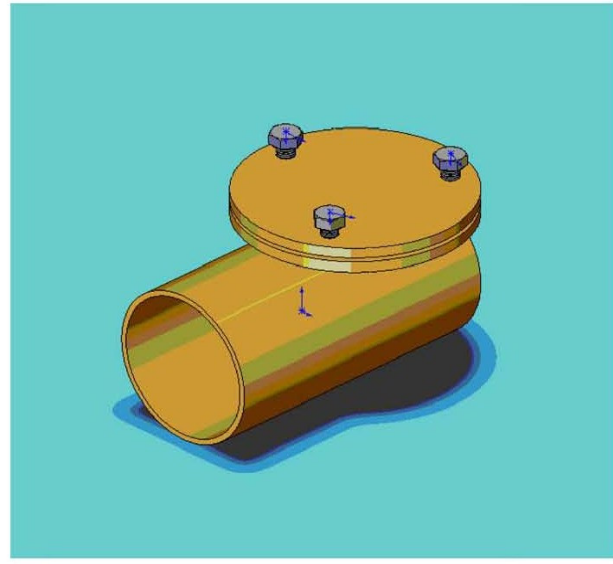

(f) 
(e) Monosparj (Walker Process Equipment Division, Chicago Bridge \& Iron Company.);

(f) Nonclog ( Enviritech, Eimoco Div.).

FIGURA 2 - Equipamentos típicos para aeração por ar difuso. (a,b) bolhas finas; (c,b) bolhas médias; (e,f) bolhas grandes. Fonte: Shiau (1995)

Vários tipos de difusores de bolhas médias e grandes estão disponíveis (Figura acima - c, d, e, f). Todos esses difusores produzem bolhas maiores que os difusores porosos e, consequentemente, têm eficiência de aeração menor. Contudo, as vantagens de baixo custo, pouca manutenção e a não necessidade de equipamentos de limpeza do ar, compensam a menor eficiência de transferência de oxigênio.

Shiau (1995) apresenta uma divisão dos aeradores de bolhas em duas categorias. Um tipo produz pequenas bolhas através de meios cerâmicos porosos e o outro utiliza orifícios ou equipamentos de cisalhamento hidráulico para produzir bolhas de ar maiores. Difusores nãoporosos estão disponíveis em grande variedade de formatos e de materiais; são construídos de metais como aço galvanizado ou inoxidável (BISCHOF el al., 1991). Eles podem ser orientados horizontal ou verticalmente, ter simples ou múltiplas saídas para liberação de ar, apresentarem passagem de ar com área variável e em planos.

Ainda segundo Shiau (1995), durante muitos anos acreditou-se que difusores de poros finos não pudessem ser utilizados em estações industriais porque as altas concentrações de matéria orgânica acabariam por entupir rapidamente os poros do difusor. Contudo, devido à crise energética, pesquisadores aumentaram seu interesse nos difusores porosos e em sua elevada eficiência de transferência de oxigênio, comparada aos sistemas de bolhas grandes. Godfrey (1987) reportou que a instalação de um difusor poroso na Estação de Tratamento de Águas Esgotos (ETE), em Albuquerque, Novo México, reduziu o custo energético em cerca de $50 \%$. O entupimento dos poros do difusor ocorreu em uma taxa que levou a pressão nos compressores a aumentar cerca de $10 \%$ em um ano. O outro exemplo da utilização de 
difusores porosos é a Estação Municipal de Tratamento de Renton, Washington, que usa membranas flexíveis de PVC. Medidas de oxigênio dissolvido no tanque de aeração mostraram que os difusores de bolhas finas são de 25 a $30 \%$ mais eficientes que os antigos difusores de bolhas grandes. Essa Estação de Renton, operando a cerca de 5 anos, nunca havia sido limpa, porém a queda na eficiência de transferência foi de apenas 6 a $8 \%$.

McCarty, em 1986, apud SHIAU (1995), reportou que engenheiros da EIMCO, Companhia de Equipamentos de Processo utilizaram um difusor em forma de disco, que gera bolhas finas, através dos poros de uma membrana elástica sintética de poli-isopreno, mantida por um suporte de polipropileno. A membrana resiste ao entupimento quando seus poros abrem sob pressão. Quando o fluxo cessa, a membrana relaxa e os poros retornam a configuração, normalmente fechada. Essa flexibilidade evita a formação de crostas inorgânicas e de limo orgânico, que causam entupimento dos poros. Testes indicaram que a membrana de poli-isopreno não exibe deterioração de suas propriedade ao menos de 6 a 7 anos.

No que diz respeito à relação entre eficiência de transferência de oxigênio e tamanho de bolhas, o trabalho de Nicholas e Ruane, 1975, segundo Shiau (1995) pode ser usado como exemplo. Eles usaram dois tamanhos de poros, 1,5 - 2,0 $\mu \mathrm{m}$, e o tamanho médio de bolhas foi medido a cerca de $30 \mathrm{~cm}$ acima do difusor. Para uma intensidade de aeração fixa de $9,1 \mathrm{~m}^{3} / \mathrm{h}$, um diâmetro médio de bolha de 0,7 milímetros foi produzido pelos poros de 1,5 a $2 \mu \mathrm{m}$. A eficiência de transferência das bolhas menores foi cerca de $10 \%$ maior que a das bolhas maiores. Assim, quanto menor a bolha, maior a taxa de transferência de oxigênio.

Motarjemi e Jameson (1978) realizaram investigação sobre a determinação do tamanho ótimo de bolhas durante a aeração de água por difusores. Eles lembraram que se as bolhas forem muito grandes, elas irão ascender à superfície muito rapidamente e não haverá tempo para haver transferência adequada de oxigênio para a fase líquida. Se, ao contrário, as 
bolhas forem pequenas demais, em pouco tempo elas terão transferido todo o seu oxigênio não trazendo, a partir daí, o efeito desejado ao sistema. Com isso, a energia necessária para gerar bolhas pequenas em uma dada profundidade seria desperdiçada.

Para relacionar a transferência de oxigênio ao tamanho das bolhas, é preciso não somente saber o diâmetro das bolhas, mas também com que velocidade as mesmas elevam-se no tanque. Muitos autores descreve sobre essa transferência de oxigênio como CALDERBANK, 1962, 1967, 1970; HABERMAN e MORTON, 1956; TREYBAL, 1981; MENDELSON, 1967; PERRY, 1984; CLIFT, 1978; BISCHOF, 1994.

O tamanho da bolha de ar depende da vazão do gás que passa através do orifício (poro) do difusor, do diâmetro do orifício, das propriedades físicas do fluido e da intensidade da turbulência no líquido. A presença de surfactantes ou outras impurezas na água pode alterar a velocidade, aumentando-a, devido à diminuição da resistência viscosa à circulação. Como conseqüência aumenta-se o arraste e a velocidade de ascensão diminui.

Mortarjemi e Jameson (1978) utilizaram duas equações para a previsão do coeficiente de transferência de massa, $K_{L} a$, nos extremos da classificação das bolhas. Assim, para bolhas muito pequenas, consideradas rígidas, a equação de Frössling propõe que:

$$
\mathrm{Sh}=0,6 \cdot \operatorname{Re}^{1 / 2} \cdot \mathrm{Sc}^{1 / 3}
$$

Higbie assume para bolhas recirculantes:

$$
\mathrm{K}_{\mathrm{L}}=2 \cdot\left(\mathrm{D} / \pi \cdot \mathrm{t}_{\mathrm{e}}\right)
$$

Onde: 
$t_{e}=$ é o tempo que a bolha demora a percorrer a distancia equivalente ao seu próprio diâmetro,

$\mathrm{T}$

$K_{\mathrm{L}}=$ coeficiente global de transferência de massa, $\mathrm{L} \mathrm{T}^{-1}$;

Segundo Motarjemi e Jameson (1978), para a transferência de oxigênio de bolhas simples de diferentes diâmetros lançadas em diferentes profundidades, é possível perceber que quanto menor a bolha, maior a quantidade e oxigênio dissolvido. Essa influência fica menos perceptível com o aumento no tamanho da bolha. $\mathrm{O}$ mesmo acontece com o aumento da profundidade do tanque. Como era esperado, bolhas contendo apenas oxigênio também apresentam maior transferência do que as que contêm ar.

\subsubsection{Controle de processos e operações}

Para introduzir os conceitos básicos na implementação do controle neste trabalho, fez-se uma pesquisa a fim de comparar o processo em questão com análogos na literatura referente a sistemas de $1^{\mathrm{a}}$ ordem. Seborg el al. (1989) e Coughanowr e Koppel (1978) fornecem diretrizes a respeito de modelos e controles para sistemas de $1^{\mathrm{a}}$ ordem, os quais foram usados neste. ( Apêndice A).

Pérez-Correa et al. (1991) desenvolveram um algoritmo de controle adaptativo não linear para regular o controle da concentração de O.D. em uma planta de tratamento de águas residuárias. Um modelo não linear simplificado do transporte de oxigênio foi empregado para estruturar o controlador, o qual foi testado em simulações. Trata-se, portanto, de uma técnica avançada de MPC (Model Predictive Control). Testes preliminares com um controlador PID mostraram respostas razoáveis para todas as perturbações realizadas, mas muito lentas e oscilatórias. A estimação adaptativa era realizada sobre parâmetros de transporte tal como o 
coeficiente de película para a massa (no caso o $O D$ ), entre outros. Os autores sugerem, via de regra, fazer estimativas "on-line" no menor número possível de parâmetros e sobre aqueles mais problemáticos ou sensíveis. A metodologia proposta mostrou-se simples e eficiente quando a priori incorporam-se informações ao processo, resultando em um controle mais robusto. Entretanto a técnica requer conhecimento aprofundado dos mecanismos envolvidos no processo.

Chachua el al (2005) estudaram viabilidades de implementação de controle otimizante em tratamento de efluentes para pequenas comunidades considerando aspectos econômicos. Neste trabalho o controle ótimo de sistema de aeração foi implementado em testes sobre o tratamento de lodo ativado industrial com a técnica "Aalternating Actived Sludge"- AAS. Os pesquisadores buscaram, através de algoritmos otimizantes, intervalos ótimos de aeração em um esquema de aerador liga-desliga. Dois objetivos foram buscados: minimização de descarga de nitrogênio ( compostos nitrogenados) e minimização de energia consumida. Para o primeiro objetivo obteve-se redução de $37 \%$ quanto ao segundo foi constatada redução de $27 \%$, mostrando ser possível obter melhoras significativas no modo de operação da planta.

Yong et al. (2005) reportaram a implementação de controle supervisório "fuzzy" em etapas de simulação para tratamento de lodo ativado. Estratégias de controle com lógica "fuzzy" foram aplicadas considerando o fluxo de carbono na zona anaeróbia e o $O D$ na zona aeróbia seguindo uma planta virtual elaborada em Simulink/Matlab. Na etapa aeróbia, o controlador "fuzzy" foi projetado em nível supervisório para impor "set-points" sobre OD no tanque de aeração, onde a regulação era feita por controle local do tipo PID. As concentrações de amônia no influente e afluente foram usadas como variáveis de entrada para o controlador “fuzzy”.Comparado com operações de $O D$ desejado constante, a vazão de ar requerida pode ser reduzida em $7 \%$ e a amônia efluente, em 18\%, usando essa estratégia. Um resultado 
interessante mostrou que os picos de concentração de amônia no efluente também puderam ser amortecidos. O interessante, é que a etapa anaeróbia, sobre o controle do fluxo de carbono, o controlador incluiu como variável de entrada, a concentração de nitratos para estimar "setpoints" sobre o fluxo de carbono. Os "set-points" quando aplicados em PI local, reduziram o carbono em até $24 \%$. A conclusão tirada após estas simulações de controle fuzzy supervisório, é haver a certeza de poder aplicar a técnica em plantas reais para melhorar a qualidade do efluente e reduzir custos operacionais.

Neste trabalho, várias técnicas de sintonia de controle PID foram usadas, especialmente ITAE, IMC ("Internal Model Control”) e Cohen-Coon, para um processo de aeração de lodo ativado. A variável controlada era o $O D$ e a manipulada, a abertura de uma válvula de admissão do ar para o aerador. Os resultados de performance desses modos de controle PID foram usados para comparações com uma técnica desenvolvida pelos autores, que é o PID "fuzzy" não-linear. A técnica baseia-se em "regras" de tentativas e erros sempre tentando minimizar um desvio de variáveis no instante atual com o instante passado e assim determinar $K_{c}, \tau_{I}$ e o $\tau_{D}$. Trata-se de um algoritmo de otimização dos parâmetros do PID, que pode ser em tempo real. Comparando-se a nova técnica com as convencionais concluiu-se que a resposta a uma mudança no "set-point" ficou mais rápida, com menores "overshoots", sem oscilações e com a vantagem de não precisar de nenhum modelo para projetar o PID. No caso de distúrbios de carga, as respostas também foram as mais rápidas, com a variação limitada a uma estreita faixa.

Ekmana et al (2006) realizaram ensaios de simulação, com posterior aplicação experimental de controle em cascata, de um processo de desnitrificação de lodo ativado por aeração em aerador compartimentado. O "set-point" de $O D$ era determinado e imposto por um PI colocado em nível superior ou supervisório. Uma planta piloto em Hammarby Sjöstad, Estocolmo, Suécia, foi usada para os ensaios de implementação em tempo real. A variável 
controlada foi o $O D$, enquanto que a manipulada foi o volume de ar inserido na aeração (vazão volumétrica). Os controladores locais eram do tipo PI. Tanto nas etapas de simulação como na implementação real, o controle se revelou de bom desempenho.

Traore et al (2005) apresentaram e discutiram resultados obtidos de controlador "fuzzy" em planta piloto de reator batelada seqüencial, que consiste em aeradores de lodo ativado. Nos primeiros ensaios foram testados métodos clássicos como PID e liga/desliga para manter o $O D$ em níveis desejados. Devido à característica não-linear do processo, o ajuste dos parâmetros do PID foi difícil, e o controle final revelou-se muito oscilatório. A amplitude de oscilação variava muito conforme os níveis de poluição na água. Com o controlador "fuzzy" baseado em regras condicionais foi possível obter performances superiores ao controle clássico, provando ser robusto e efetivo para o controle de $O D$.

\subsection{Considerações finais}

Os resultados obtidos por diversos autores trabalhando com a aeração por ar difuso permitiram que fosse elaborado um plano de trabalho simples, porém de grande utilidade para avaliar o controle do processo de transferência de oxigênio. As condições operacionais, variáveis analisadas e procedimento experimental estão apresentados a seguir.

A apresentação da revisão bibliográfica foi subdividida, no sentido mostrar a importância da busca de qualidade de águas, obter fundamentos sobre o mecanismo de transferência de oxigênio em água, buscar conhecimento sobre o processo de aeração e aeradores e, finalmente, fornecer respaldo para a otimização operacional através de controle automático. 


\section{MATÉRIAIS E MÉTODOS}

\subsection{Equipamento Experimental}

A planta experimental (FIGURA 3) um canal aerado sem agitação mecânica encontrase no laboratório de Hidráulica Ambiental, localizado no CRHEA-SHS-EESC-USP (Broa, Itirapina, SP). A princípio, foi usado um canal aberto de $5 \mathrm{~m}$ (comprimento) x 350mm (altura) x 200mm (largura.) de acrílico para visualização das plumas de bolhas. Esse canal adaptado para aerador está instalado em uma planta piloto, a qual foi usada para ensaios de cavitação (Carvalho, 1997). A alimentação do canal é usualmente feita pela captação de água do ribeirão do Lobo por um sistema elevatório constituído de uma bomba semi-axial KSB (125cv capacidade. de 250 1/s) e um reservatório de concreto de 9,5m de altura (capacidade. de

$60 \mathrm{~m}^{3}$ ). Neste trabalho, utilizou-se um sistema de reciclagem da água usando uma bomba centrífuga de $0,75 \mathrm{cv}$. 


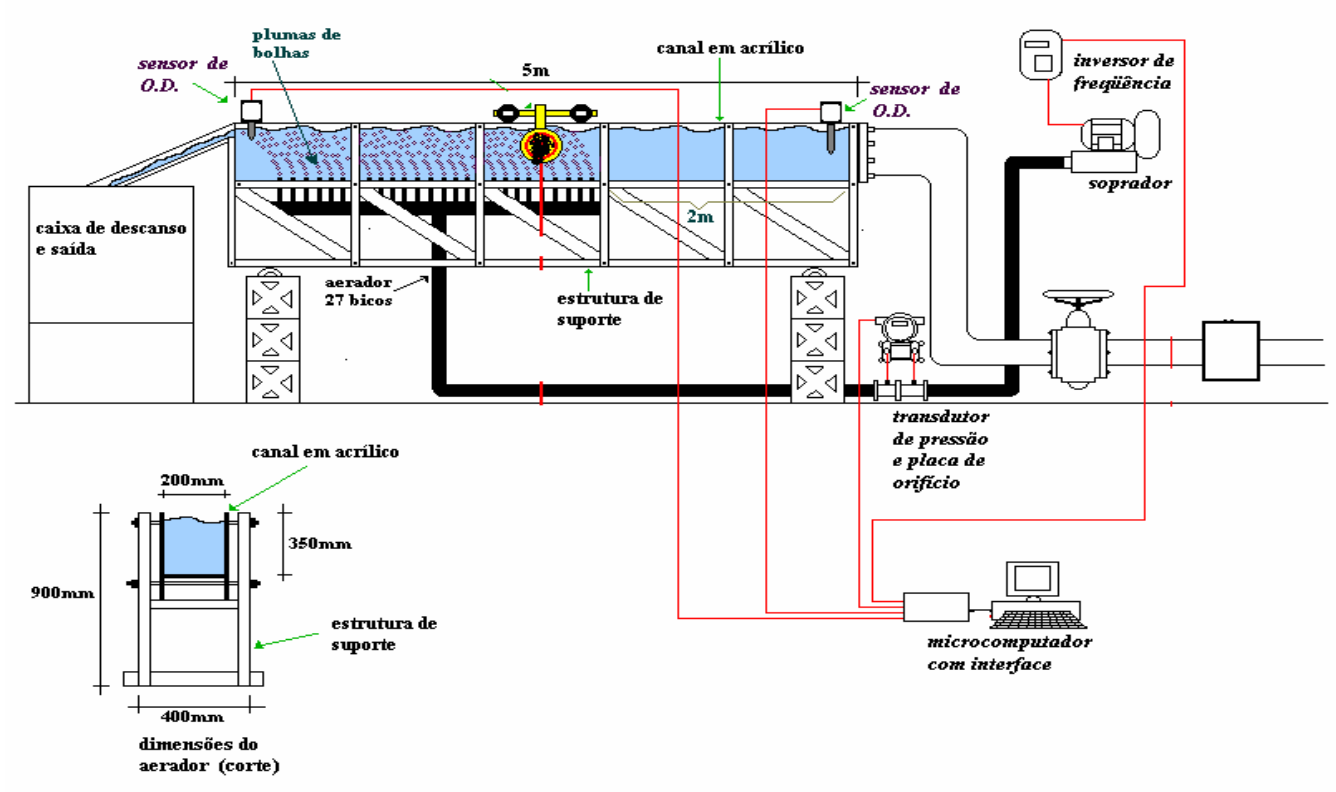

FIGURA 3 - Planta experimental do tanque de aeração adaptado de um canal aberto. Dimensões. Disposição do sistema para aquisição de dados e controle.

A vazão de água admitida no canal é medida por um rotâmetro e fixados em torno de $12 \mathrm{~L} / \mathrm{min}$. Os aeradores estão inseridos na linha central do fundo (3 metros de comprimento), igualmente distanciados $(10 \mathrm{~cm})$ e dispostos longitudinalmente. A saída do aerador é feito, por transbordamento em um bocal apropriado.

Para fins de controle, um sensor-transmissor de oxigênio dissolvido foi instalado na saída do aerador e outro na entrada. A vazão de ar é regulada por um inversor de frequiência atuando sobre a rotação do soprador. Os aeradores foram colocados a $2 \mathrm{~m}$ da entrada para evitar a não uniformidade de escoamento dessa região.

\subsection{Sistema de Deaeração da água}

O primeiro passo para a realização dos testes foi a montagem de um sistema deaerador, com a finalidade de diminuir a concentração inicial do $O D$ na água. Havia duas 
possibilidades de promover a deaeração: através de método químico ou de método mecânico.

Para se produzir déficit de oxigênio na água, foi usado a desoxigenação química. Neste caso a água era deaerada para valores próximos de $1 \mathrm{ppm}$, usando sulfito de sódio para reagir com o oxigênio pela reação:

$$
{ }^{-} \mathrm{SO}_{2}+1 / 2 \mathrm{O}_{2} \rightarrow{ }^{--} \mathrm{SO}_{3}
$$

A água utilizada foi da rede pública (CRHEA-SHS-EESC-USP), cujo teor de oxigênio dissolvido encontra-se na faixa de 6 a $7 \mathrm{mg} / \mathrm{L}$, sendo que a solução química de deaeração reduzia este valor para uma faixa de 0,5 a $2 \mathrm{mg} / \mathrm{L}$. Iniciando o processo de deareação, que dura aproximadamente 4 a 6 horas para atingir a faixa desejada de oxigênio dissolvido na massa de água. O ponto final para a deaeração era monitorada pelos sensores de OD instalados na bancada no início e no final do canal, enquanto a temperatura era praticamente constante na faixa de $25^{\circ} \mathrm{C}$ ambiente. Quando o processo de deaeração estabelecia estado estacionário e a concentração inicial de oxigênio dissolvido caía para valores aceitáveis para iniciar a reaeração $(O D) \approx 1,0 \mathrm{mg} / \mathrm{L})$ era dada a partida no ensaio de aeração para determinação dos parâmetros do modelo empírico.

Na FIGURA 4, é mostrado o recipiente onde se colocava a solução de sulfito na bancada para deaeração da água. 


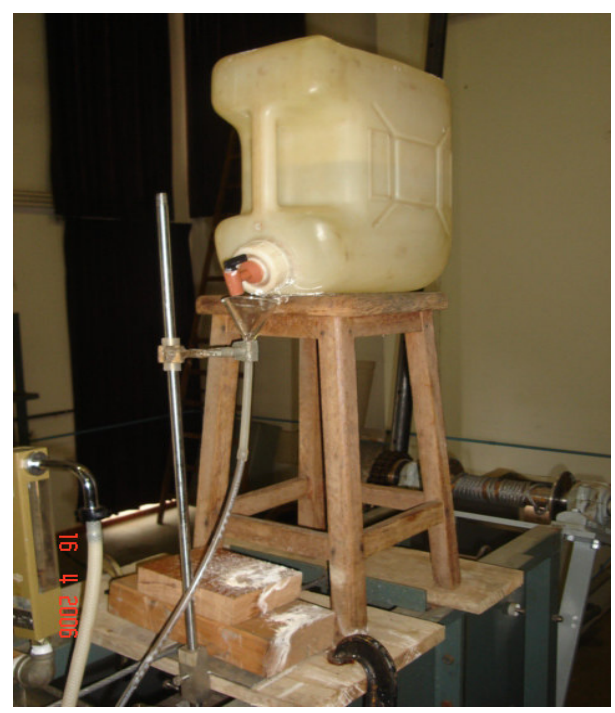

FIGURA 4: Sistema de deaeração da água.

\subsection{Condição da temperatura}

Os ensaios foram realizados em temperatura ambiente. A massa de água a ser reoxigenada e o local dos ensaios sempre estiveram em temperaturas próximas de $25^{\circ} \mathrm{C}$.

A bancada possui sensores que medem o $O D$, além de medir a temperatura da água. São sensores eletrônicos, marca Rosemount Analytical Model 1055, PWR: 115/230 $\mathrm{VAC}=15 \%, 50 / 60 \mathrm{~Hz}$, aproximadamente $6 \%, 8 \mathrm{~W}$, com dispositivo de saída de sinal para equipamento periférico. Desta forma, foi possível determinar as variações de temperatura da água que, naquela ocasião dos ensaios, não ultrapassaram a faixa de $25^{\circ}$ a $26^{\circ} \mathrm{C}$. O processo de reoxigenação por meio de produção de borbulhamento no meio líquido não produz aquecimento apreciável na massa de água. Os dados de temperatura também foram registrados da mesma forma que as medidas de oxigênio dissolvido. As temperaturas médias nos experimentos registraram variações de aproximadamente 0,3 a $0,7^{\circ} \mathrm{C}$ entre um ensaio e outro, o que não produz modificações substanciais nos mecanismos dissipativos. Destarte, a temperatura não foi analisada. 


\subsection{Modelo de $1^{\text {a }}$ ordem}

O presente trabalho utiliza a equação empírica clássica de um modelo de primeira ordem em resposta a um degrau na entrada como descrito abaixo:

$$
Y=Y i+K A\left[1-e^{(\theta-t) / \tau}\right]
$$

Em que:

$Y=\operatorname{resposta}(\mathrm{ppm})$

$Y i=$ estado estacionário inicial $(\mathrm{ppm})$

$K=$ ganho do processo $(\mathrm{ppm} / \mathrm{rpm})$

$A=$ amplitude do degrau na variável de entrada (rpm)

$\theta=$ tempo de atraso (s)

$t=$ tempo $(\mathrm{s})$

$\tau=$ constante de tempo $(\mathrm{s})$

\subsection{Calibração do medidor de vazão ( placa de orifício )}

Para a calibração da placa de orifício foi usado um manômetro diferencial de água em "U” e um anemômetro analógico para medir a velocidade do ar.

Assim, uma determinada diferença de pressão produzida no manômetro corresponde a uma determinada vazão. Nas perturbações degrau foram utilizadas três vazões para entrada de ar relacionadas às rotações : 1300 rpm, 2400 rpm e 3500 rpm.

A FIGURA 5, mostra a calibração para a placa de orifício. A equação ajustada foi introduzida na aquisição on-line. 


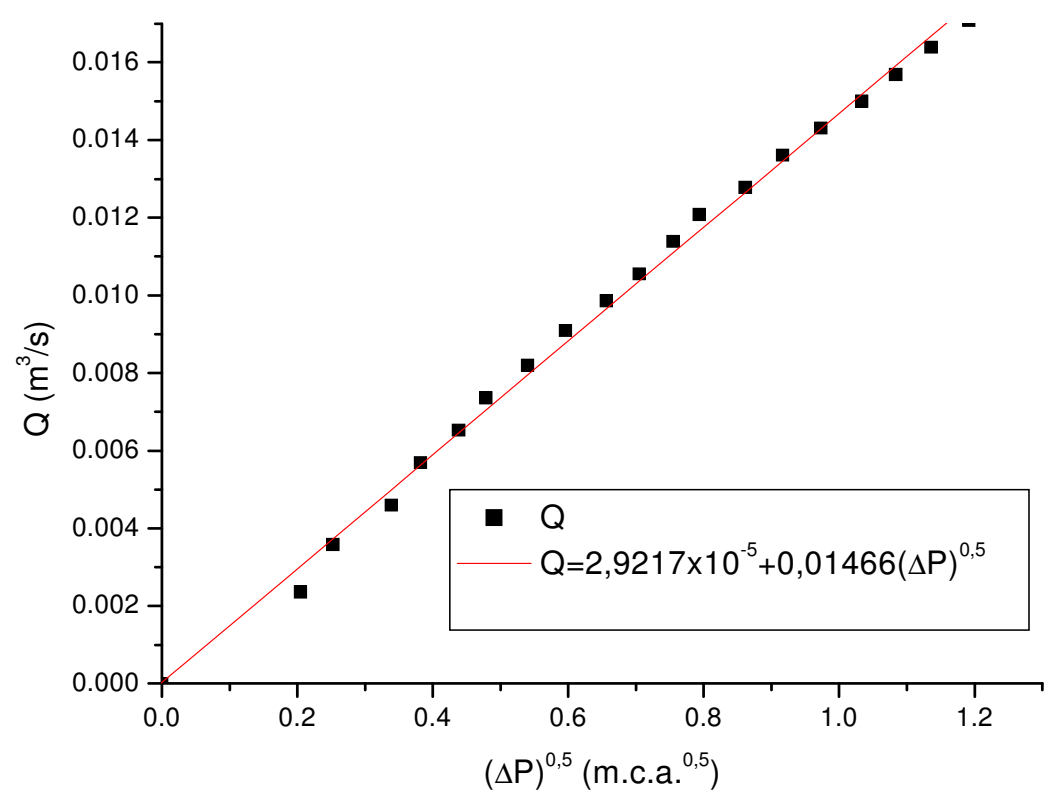

FIGURA 5 - Curva de calibração do medidor de vazão ( placa de orifício )

Para identificar-se o modelo linear (tipo black-box ou "caixa preta”) para ajuste do controlador, um método de perturbação, ou estímulo-resposta (estímulo: degrau na variável manipulada relacionada à quantidade de oxigênio gasoso fornecido ao sistema; resposta: concentração de oxigênio dissolvido) empregou-se sulfito de sódio para consumir o oxigênio até níveis pré-estabelecidos usando a estequiometria da reação.

Na implementação do controle, assumiu-se o sistema como SISO (simples entrada simples saída) no qual a variável a ser controlada foi a concentração de oxigênio dissolvido na saída do tanque $(O D)$ e a variável manipulada foi a rotação no soprador (rot) associada à vazão de ar alimentada na aeração $(Q)$. A vazão de líquido $(W)$ foi considerada distúrbio variável, uma vez que em situações reais de tratamento de efluente, por exemplo, ela está sujeita a flutuações. A implementação das técnicas de controle (PID) seguiu a estrutura apresentada a seguir: 


$$
p_{n}=\bar{p}+K_{c}\left[e_{n}+\frac{T}{\tau_{I}} \sum_{k=1}^{n} e_{k}+\frac{\tau_{D}}{\Delta t}\left(e_{n}-e_{n-1}\right)\right]
$$

Em que:

$P_{n}=$ sinal de saída do controlador PID;

$\bar{p}=$ valor "bias" do sinal de saída ( valor de saída quando $\mathrm{e}_{\mathrm{k}}=0$ ) do PID;

$K_{c}=$ ganho do controlador PID;

$\square_{I}=$ tempo de integração ou intervalo de repetição da ação proporcional do PID;

$T=$ intervalo de amostragem, $\mathrm{T}$;

$\square_{\mathrm{D}}=$ tempo derivativo do PID, T;

Ajustar os parâmetros do controlador PID é determinar $K_{c}, \tau_{I}$ e $\tau_{D}$ de modo que o sistema, em malha fechada, fosse estável e robusto. Um ajuste segundo o critério ITAE ( Integral of the time-weighted absolute - integral do erro absoluto ponderando no tempo) foi usado para obter esses parâmetros e foi feita uma sintonia fina de campo antes dos ensaios.

Vale a pena dizer que todos os algoritmos de controle foram reestruturados em linguagem $\mathrm{C}$, bem como os de monitoração e aquisição de dados (todos em tempo real), a partir dos programas desenvolvidos em CORRÊA (2000).

A análise dos resultados referentes à qualidade do modelo de identificação foi feita mediante a regressão com dados experimentais em malha aberta. O desempenho do controle consiste na observação dos históricos das variáveis da estratégia implementada. Serão levadas em consideração, também, a estabilidade "ringing e off-set", a performance e a robustez dos controladores. 


\section{RESULTADOS E DISCUSSÕES}

\subsection{Identificação do Processo}

Em todos os ensaios de aeração não foi considerado o mecanismo de reaeração superficial, possivelmente influente, uma vez que a superfície da água apresentava intensa turbulência.

Até o momento concluiu-se a identificação do processo como modelo de $1^{\mathrm{a}}$ ordem. Apresentam os estímulos degrau positivo e negativo na variável de entrada com as respectivas respostas.

A FIGURA 6 mostra os pontos experimentais obtidos na fase da resposta frente ao estímulo degrau positivo na variável manipulada rot ( rotação do soprador - rpm ).

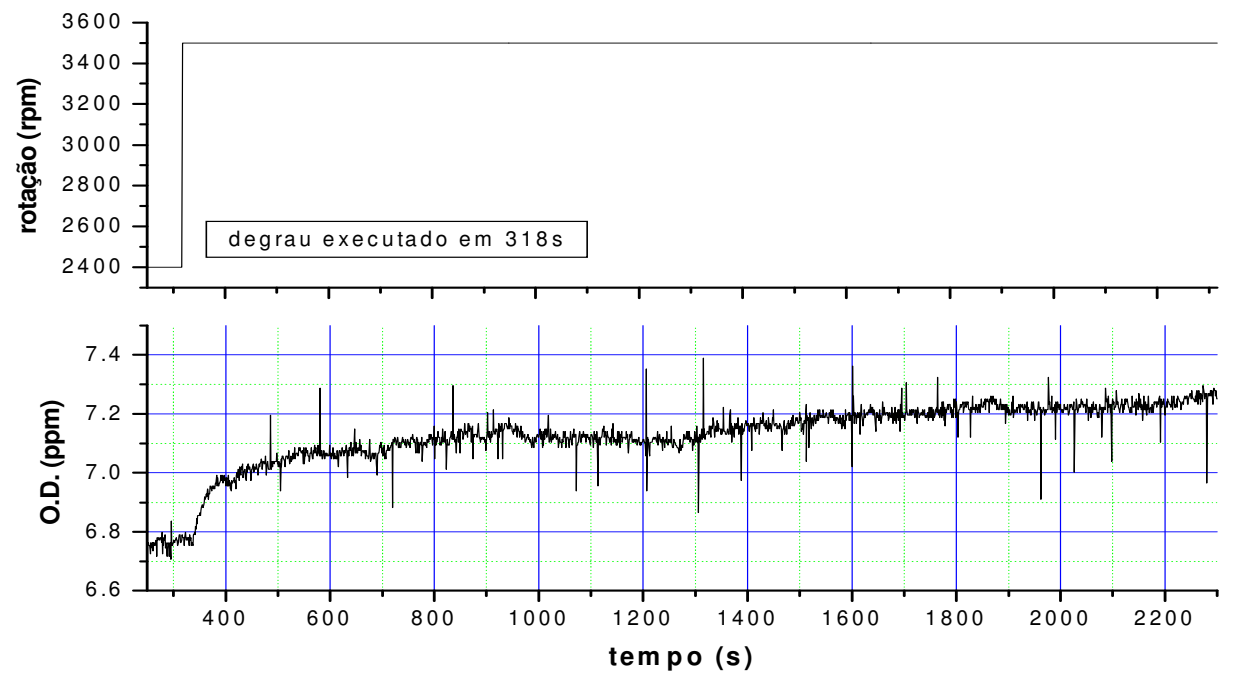

Figura 6 - Perturbação para degrau positivo na rotação. 
A FIGURA 7 mostra o modelo (linha contínua-verde) ajustado aos dados experimentais (linha ondulada - azul). Observa-se muito ruídos na variável $O D$, proveniente do instrumento (um filtro deverá ser incorporado no programa posteriormente). O que se fez foi tomar o melhor ajuste visual seguindo uma tendência média dos valores de $O D$ (o controlador deverá ser robusto para superar os desvios de modelo).

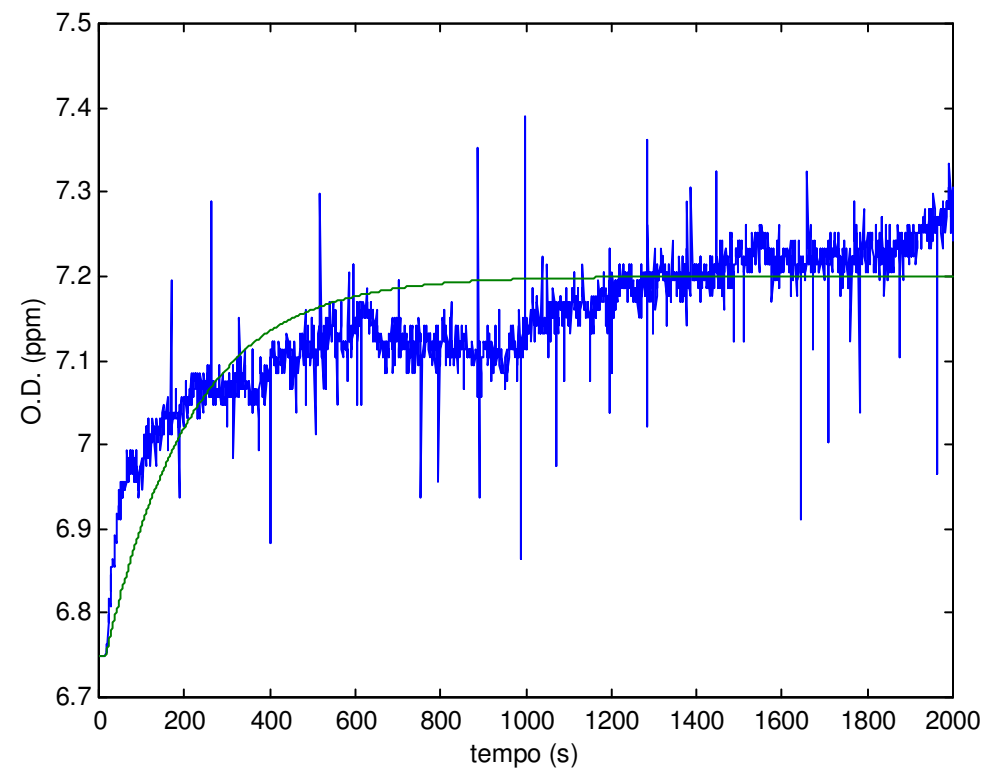

Figura 7: Resposta ao degrau positivo. Azul: dados experimentais. Verde: ajuste pelo modelo de $1^{\mathrm{a}}$ ordem.

Desta forma, obtém-se os seguintes valores:

$K=4.0909 \times 10^{-4}$ p.p.m/r.p.m.

$\tau=250 \mathrm{~s}$

$\theta=16 \mathrm{~s}$

A FIGURA 8 mostra os pontos experimentais na fase a partir da resposta frente ao estímulo degrau negativo na variável manipulada. 


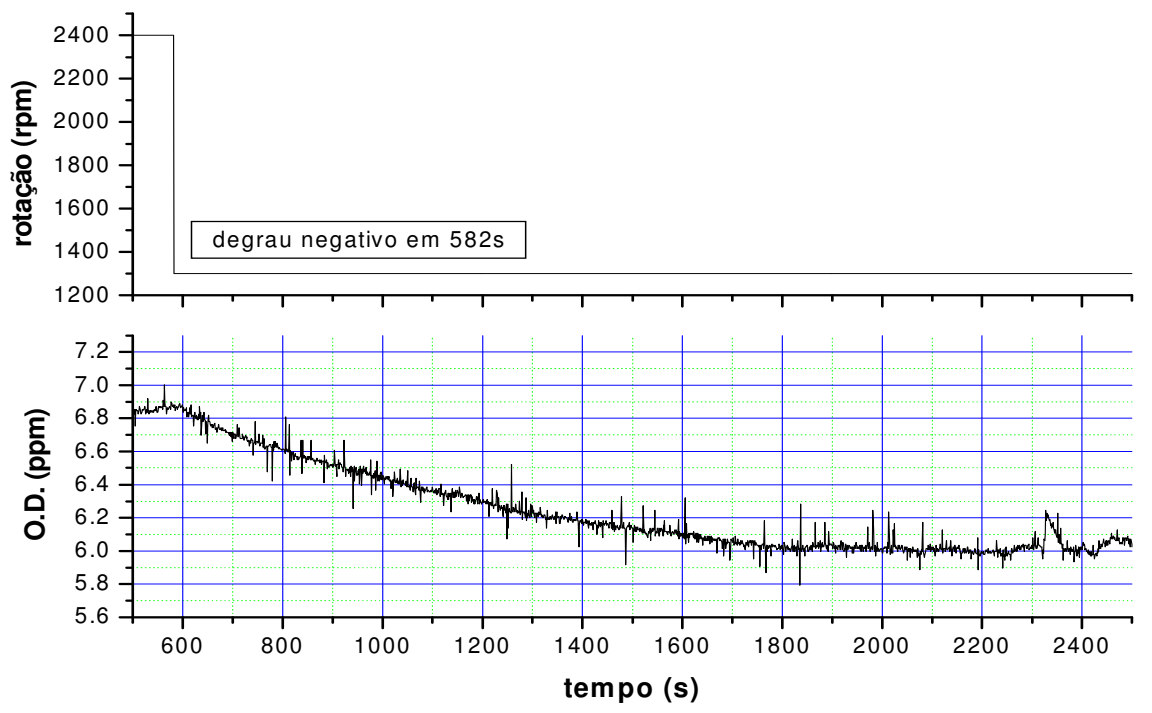

Figura 8 - Perturbação para degrau negativo na rotação

A FIGURA 9 mostra o modelo (linha contínua-verde) ajustado negativos aos dados experimentais (linha ondulada - azul). As mesmas observações para o degrau positivo são válidas aqui.

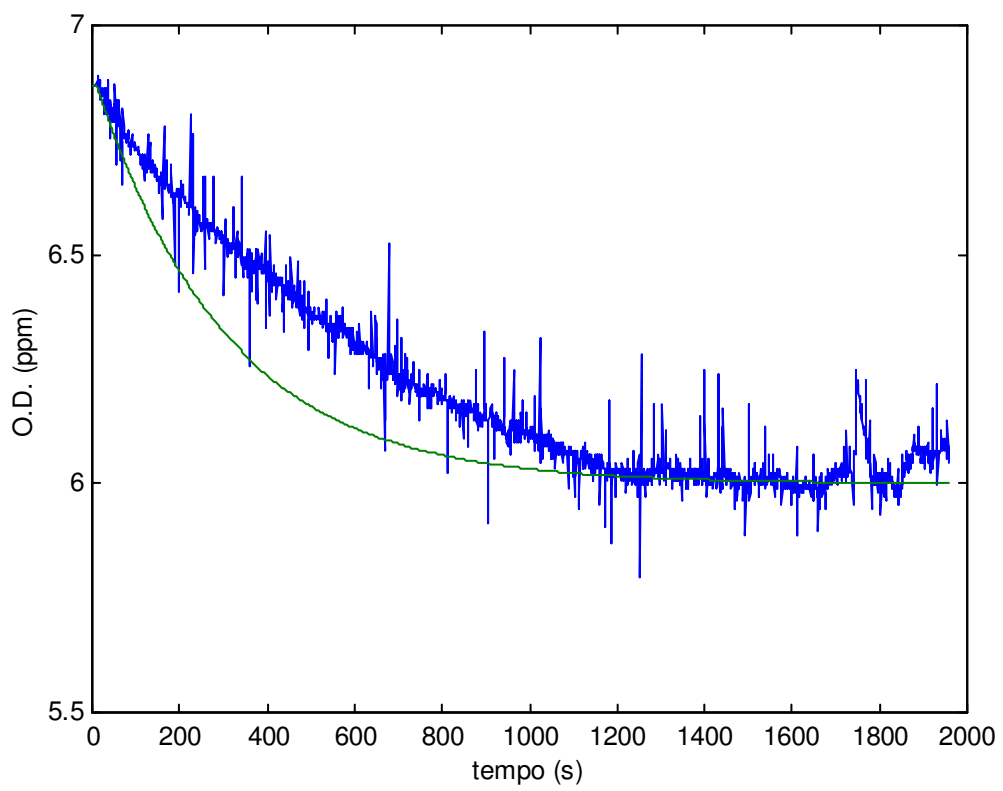

Figura 9 - Resposta ao degrau negativo. Azul:dados experimentais. Verde: ajuste pelo modelo de $1^{\text {a }}$ ordem. 
Desta forma, forma obtidos os seguintes valores:

$K=7.9091 \times 10^{-4}$ p.p.m/r.p.m.

$\tau=300 \mathrm{~s}$

$\theta=10 \mathrm{~s}$

Nos ensaios de estímulo degrau positivo e negativo obtivemos valores respectivos de $K, \tau$ e $\theta$. Na implementação do controle, a sua sintonia (parâmetro do PID e matriz dinâmica no MPC) é baseada nos valores médios dessas constantes, ou seja,

$$
\begin{aligned}
& \mathrm{K}_{\text {médio }}=\underline{\mathrm{K}}_{\mathrm{pos}}+\mathrm{K}_{\text {neg }}=\frac{4.0909 \times 10^{-4}+7.9091 \times 10^{-4}}{2}=5.9999 \times 10^{-4} \mathrm{p} \cdot \mathrm{p} \cdot \mathrm{m} / \mathrm{r} \cdot \mathrm{p} \cdot \mathrm{m} . \\
& \tau_{\text {médio }}=\tau_{\frac{\text { pos }}{2}+}+\tau_{\text {neg }}=\frac{250+300}{2}=275 \mathrm{~s} \\
& \theta_{\text {médio }}=\theta_{\text {pos }} \frac{+}{2} \theta_{\text {neg }}=\frac{16+10}{2}=13 \mathrm{~s}
\end{aligned}
$$

\subsection{Controle do Processo}

Identificado o sistema, procurou-se ajustar os parâmetros do PID seguindo a técnica ITAE conforme descrita no - Apêndice A. Foram obtidos os seguintes valores para o caso de mudança no "set point", para um intervalo de amostragem de $T=100$ s:

$K_{c}=21526 \mathrm{rpm} / \mathrm{ppm}$

$\tau_{I}=348,5 \mathrm{~s}$

$\tau_{D}=5,0 \mathrm{~s}$

Esses valores foram implementados no experimento sem sucesso, pois o valor de $K_{c}$ amplificou demasiadamente os sinais de rot. Necessitou-se, portanto, de uma sintonia fina de 
campo e, após algumas tentativas, o valor adequado para o ganho do controlador foi $K_{c}=100$ rpm/ppm.Os outros parâmetros, $\tau_{I}$ e $\tau_{D}$, não necessitaram ajuste fino. Com a sintonia refinada, os ensaios puderam prosseguir satisfatoriamente.

Ensaios com alteração do "set point" são mostrados nas FIGURAS 10 e $11 \mathrm{Na}$ FIGURA 10 tem-se o histórico de $O D$ e rot para um degrau negativo de cerca de $9 \%$ no valor desejado de $O D$. Observou-se controle estável dentro da faixa operacional, com um pequeno "overshoot" e suave assentamento. Os movimentos de rot apresentaram-se de pequena amplitude sem qualquer movimento abrupto.

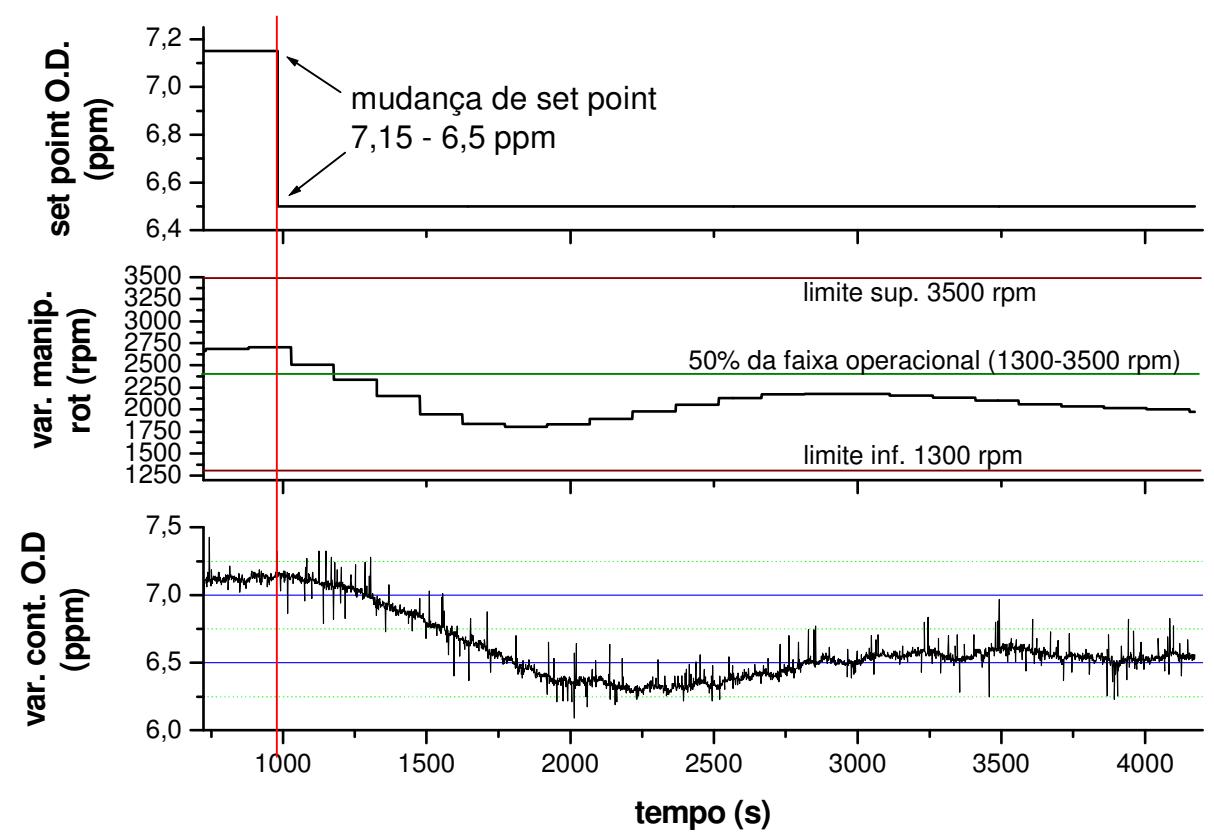

Figura 10 - Controle PID. Mudança de "set point" em degrau negativo de 9\%.

Na FIGURA 11, tem-se dois degraus positivos em torno de 7\% saindo da condição de equilíbrio atingida no ensaio anterior. Com relação ao primeiro degrau, valem as mesmas observações consideradas no ensaio anterior. Entretanto, no segundo degrau, embora o 
controlador respondesse precisamente, houve saturação de rot no valor máximo de 3500rpm.

O PID não é capaz de detectar e contornar essa situação. Seria necessária uma rotina de otimização no algoritmo considerando os limites superiores e inferiores das variáveis. Possivelmente, pode haver alguma histerese, a qual resulta em não-linearidades, não previstas no modelo de $1^{\mathrm{a}}$ ordem médio obtido na etapa anterior de identificação (Secção 5.1). O que pode, ser feito é elaborar uma rotina com parâmetros do PID diferenciados, autoprogramáveis, dependendo da região da resposta, ou, ainda, simplesmente programar uma variação no set point suave (não em degraus) e lenta o bastante para evitar movimentos exagerados em rot. Esse amortecimento em rot possivelmente evitaria chegar ao extremo de saturação.

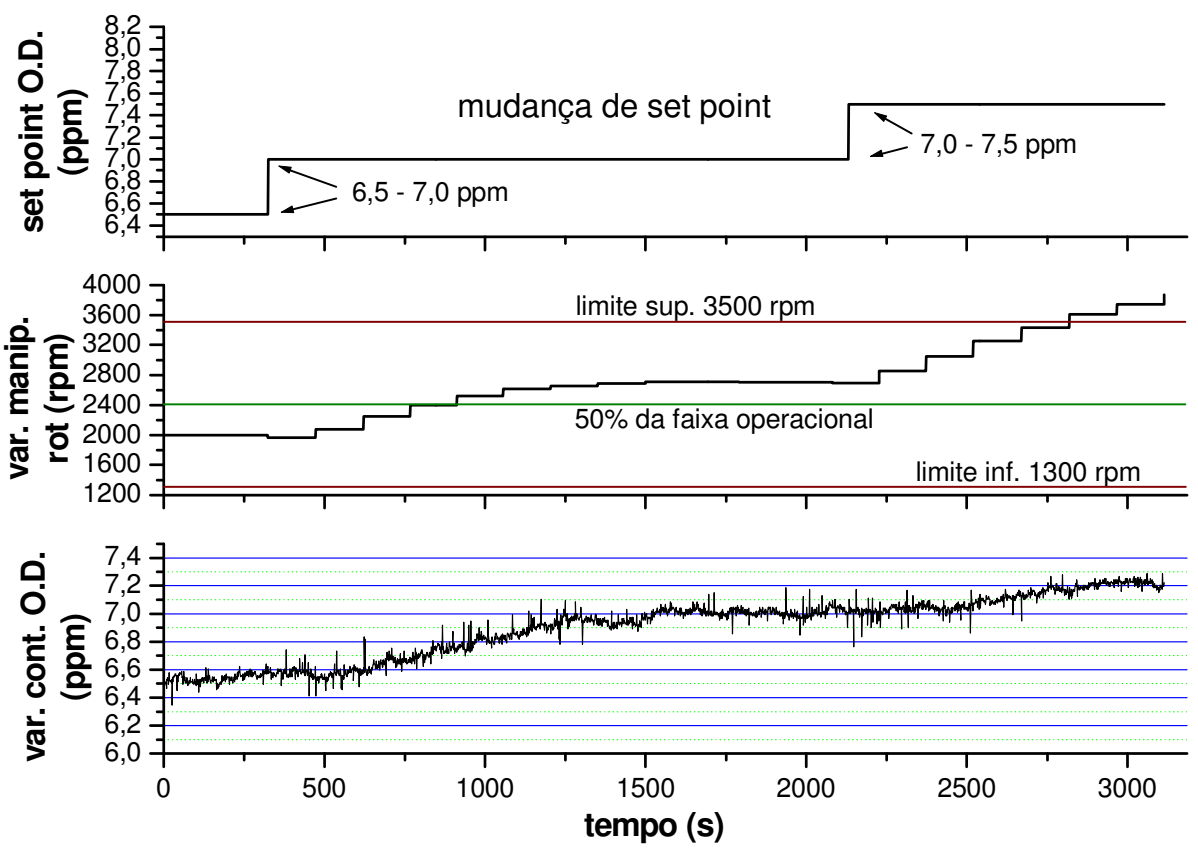

FIGURA 11 - Controle PID. Mudança de "set point" em degraus positivos de aproximadamente $7 \%$.

Na FIGURA 12 é apresentado o histórico de variáveis para o controle PID considerando distúrbio de carga. No caso, a carga foi a variável (somente medida, sem 
controle ou manipulação) vazão de água. Trata-se de um ensaio que simula situações encontradas em tratamento de água ou esgoto, pois a descarga do efluente é imprevisível e incontrolada ou manipulada (o que se tem são valores médios, obviamente). O "set point" foi mantido constante em 7,0 ppm e a vazão de água teve seu valor reduzido em 50\%, caindo de 12,0 para $6,0 \mathrm{~L} / \mathrm{s}$ através de estrangulamento rápido (quase abrupto) de uma válvula do sistema de reciclo da água no canal.

Observa-se uma tendência de $O D$ ao decaimento abaixo de 7,0 ppm, tendo uma compensação eficiente por rot, o qual foi capaz de restaurar o equilíbrio novamente para essa nova situação de menor vazão de água. Atribui-se a tendência de decaimento de $O D$ ao fato de aumentar a concentração de sulfito de sódio dentro do canal exigindo mais oxigênio para consumi-lo. É importante ressaltar que a taxa de aplicação do sulfito de sódio manteve-se praticamente inalterada em todos os ensaios para levar a redução de $O D$ na entrada a um valor abaixo de 1 ppm nesses ensaios de controle.

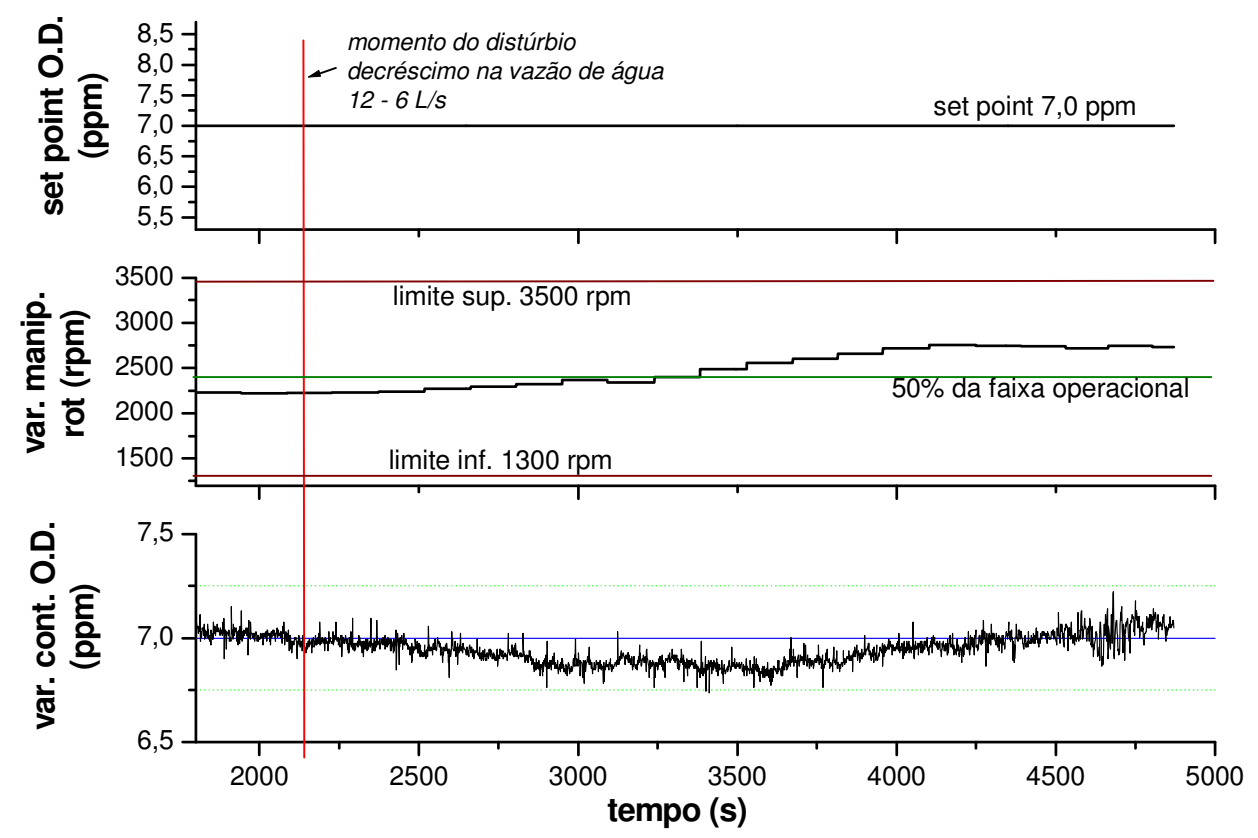

FIGURA 12 - Controle PID. Distúrbio na carga 'vazão de água' em degrau negativo de $50 \%$. 


\section{CONCLUSÕES E SUGESTÕES}

\subsection{Conclusôes}

O controle PID revelou performance satisfatória dentro de suas limitações com relação ao modelo identificado.

A técnica ITAE de ajuste dos parâmetros do PID somente resultou $\tau_{I}$ e $\tau_{D}$ adequados, sendo que o $K_{c}$ se revelou indevidamente elevado, amplificando demasiadamente os movimentos em rot, gerando instabilidade.

A sintonia de campo de $K_{c}$ por tentativas foi satisfatória, estabilizando o controle devidamente.

O modelo de $1^{\mathrm{a}}$ ordem identificado por estímulo degrau revelou-se adequado e robusto. Evidentemente, por ser modelo médio, histereses e outras não-lineridades são ocultas, levando a erros no controle da saturação. Isso pode ser contornado com alterações no algoritmo, como dito anteriormente. Contudo, é um modelo de decaimento exponencial empírico representativo.

O equipamento experimental instrumentado mostrou-se adequado para o processo de aeração, ressaltando-se necessidades de otimização, como dispersores de bolhas mais eficientes e refrigeração do ar antes do borbulhamento. Embora a água mantenha praticamente constante a temperatura do ambiente o ar entra aquecido nas bolhas devido à dissipação térmica na linha do soprador. $\mathrm{O}$ ar quente na bolha reduz a transferência do oxigênio para a 
água, sendo esse fato um provável motivo para impossibilitar altos valores de OD próximos de saturação (cerca de 8,0 a 9,0 ppm para $25-30^{\circ} \mathrm{C}$ do ambiente).

\subsection{Sugestões}

- $\quad$ comparar estratégicas de controle do tipo convencional com estratégicas avançadas;

- $\quad$ implementação do controle MPC, no caso do controle preditivo DMC, com a matriz dinâmica também construída a partir da resposta frente ao estímulo degrau na variável manipulada;

- $\quad$ considerar o problema de restrição na variável de saída O.D. ( hard constraint ) ou na variável manipulada rot, através de uma otimização "on-line" à qual pode ser aplicado um método $Q P$ ( 'programação quadrática' com uso de multiplicadores de Lagrange na formulação da função objetivo para tratar restrições.) no algoritmo do DMC, ou seja, aplicar o QDMC “Quadratic Dynamic Matrix Control”. 


\section{REFERÊNCIAS BIBLIOGRÁFICAS}

ATV - ABWASSER TECHNISCHE VEREINIGUNG (1987) -Umwandlung und Elimination von Stickstoff im Abwasser. Arbeitsbericht der ATV - Fachausschüse 2.6 und 2.8. Korrespondenz Abwaser, v.34. Jahrgang, p. 77-85.

ABREU, R. M. (1987). Monitoramento da qualidade da água no Estado de São Paulo e na França. Ambiente, v.1,n.3,p.109-112.

ALMEIDA NETO, E.; RODRIGUES, M.A.; ODLOAK, D.(2000) Robust Predictive Control of a Gasoline Debutanizer Column. Brazilian Journal of Chemical Engineering, vol. 17, $\mathrm{n}^{\mathrm{o}} 4$ 7, p.967-977.

AMERICAN SOCIETY OF CIVIL ENGINEERS (ASCE) 1999 - Standard, Measurement of oxygen transfer in water, New York, Jul., p. 39.

BARBOSA JÚNIOR, A. R. (1989). Desenvolvimento de metodologia para a determinação do coeficiente de reaeração dos escoamentos naturais da água com o emprego de traçador gasoso, Dissertação de Mestrado, Departamento de Hidráulica e Saneamento, Escola de Engenharia de São Carlos, Universidade de São Paulo, USP.

BARBOSA JÚNIOR, A. R. (1997). Uso de traçadores na determinação de parâmetros de qualidade em escoamento naturais de água. São Carlos. 187 p. Tese(Doutorado) - Escola de Engenharia de São Carlos, Universidade de São Paulo, USP.

BEAUMONT, P. (1975). Hydrology. In: WHITTON, B. A. River Ecology. Londron, Blackell Scientific Publications. P. 538-564.

BENNET, J. P.; RATHBUN, R. E. (1972) - Rearation in open-channel flow. Geological Survey Professional. Paper 737. United states Departament of Interior, Washington, 75p.

BISCHOF, F.; SOMMERFELD, M.; DURST, F. (1991). Chemical Engineering Science, v. 46, p.3113.

BISCHOF, F., et al. (1994). Aeration Technology, v.187, Book G00865

BISWAS, A. K. (1991) Effective monitoring of lake waters. In: HASHIMOTO, M.; BARRET, B.F.D. (Editors) Guidelines for lake management. ILEC, UNEP. Section 3.2,p. 8396 
BISWAS, A. K. (1990) Objetives and concepts of environmentally-sound water management. In: THAN, N.C.; BISWAS, A.K. Environmentally-sound water management. Delhi, Oxford University Press. P.30-58

BRASIL, Leis etc (1974). Código de Água: legislação subseqüente e correlata. Rio de Janeiro. Ministério das Minas e energia, DNAEE.

BRASIL, Leis etc (2005). Ministério do Desenvolvimento Urbano e Meio Ambiente. Conselho Nacional do Meio Ambiente. Resolução $n^{\circ} 357$ de 17 de março de 2005. Dispõe sobre a classificação dos corpos de água e diretrizes ambientais para o enquadramento das águas doces, salobras e salinas do território nacional. Diário Oficial da União, Brasília, 30 de março de 2005. Seção I, p.11356.

BRASIL, Leis etc. (1976). Portaria $\mathrm{n}^{\circ} 13$ de 15 de janeiro de 1976. Classifica as águas interiores do Território Nacional. Ministério do Interior. Diário Oficial da União, Brasília, 12 de maio e 1976.p. 5881.

CALDERBANK, P.H. e MOO-YOUNG, M. (1962). Chemical. Enginnering. Science, v.16, p.39.

CALDERBANK, P.H. (1967). Trans. Institute Chemical Enginnering., 45 CE209.

CALDERBANK, P. H., JOHNSON, D. S. L. e LONDON, J. (1970). Chemical. Enginnering Science, v.25, p.235.

CARVALHO, P. D .(1997). Aeração de Escoamento de Alta Velocidade em Canais de Forte Declividade. São Carlos, SP, EESC-USP. 387p. (Tese).

CHACHUAT, B., ROCHE, B., LATIFI, M.A. (2005). Optimal aeration control of industrial alternating activated sludge plants. Biochemical engineering Journal 23, pg. 277-289.

CIRPKA, O., VIESSMAN JR.W. (1993) - Environmentally Science Technologic., v 27, n.10, p.2086.

CLARKE, D.W.; MOHTADI, C.; TUFFS, P.S. (1987). Generalized Predictive Control - Part I. The Basic Algorithm, Automatica, vol. 23, n. 2, p. 137-148.

CLARK, J.W.; VIESSMAN JR.W.; HAMMER, M.J. (1971) Oxigen transfer and air requirements, Water Supply and Pollution control, 2nd ed., edited by internacional Text Book Company, pp. 523-529.

CLIFT, R., GRACE, J.R., WEBER, M.E.(1978). Bubbles, drops and particles, Academic Press, New York.

COIMBRA, R.M. (1991). Monitoramento da qualidade da água. In: PORTO, R.L.L. el al. Hidrologia ambiental, São Paulo, USP/ABRH (coleção ABRH de Recursos Hídricos, v.3). p.392-411.

COUGHANOWE, D. R.; KOPPEL, L. B. (1965). Análise e Controle de Processos, Editora Guanabara Dois - Rio de Janeiro. 
CORRÊA, N.A.(2000). Projeto de Parâmetros e Tratamento de Restrições em Controlador Preditivo DMC. São Carlos, SP, PPG-EQ/UFSCar. 103p. (Dissertação).

CUTLER, C.R. \& RAMAKER, B.L. (1979). Dynamic Matrix Control -a Computer Control Algorithm. In: AIChE National Meet, 86, Houston, Texas, EUA, 1979. Anais. Houston, abril, Paper 51-B.

ECKENFELDER , S.J.; ACHMAN, D.; HORNBUCKLE; BAKER, J.E. (1980) Volatilization of PCBs from the great lakes. In: Air-water Mass Transfer $-2^{\text {nd }}$ INTERNACIONAL SYMPOSIUM ON GAS TRANSFER AT WATER SURFACES, WILHELM, S. C. \& GULLIER, J.S. eds, ASCE. New York, p. 400-412.

EKMANA, M.; BJÖRLENIUS, B.; ANDERSON, M. (2006) Control of the aeration volume in an activated sludge process using supervisory control strategies. Water Research (in Press).

GARCIA, C.E. \& MORSHEDI, A.M.(1986). Quadratic Programming Solution of Dynamic Matrix Control (QDMC). Chem. Eng. Commun., vol. 46, no 73.

GILBERT, R. O. (1987). Statistical methods for environmental pollution monitoring. New York, Van Nostrand Reinhold.

GOLDFREY, M.F.(1987) Reoxygenation and deoxygenating of industrial waste in a bath reator. In; International Symposium on air - water gas transfer, University of Erlangen, Erlangen, German.

KOIDE K., HAYASHI T., SUMINO K., IWAMOTO S., (1976). Mass transfer from single bubbles in a aqueous solution of sufactants. Chemical Enginnering Science 31, p 963-967.

HABERMAN, W.L.; MORTON, R. K. (1956). Trans. American Sociedaty Civil Enginnering. v.121, p.227.

HIGBIE, R. (1935) - The rate of absorption of a pure gas into a still liquid during short periods of exposure. Journal of American Inst. Chem. Engineers Trans, v.31, p. 365-390.

IRWIN, F.; WILLIAMS, I.R. (1986). Catchments as planning units. Journal of Soil Conservation, v. 42, n.1, p.6-9.

YONG, M.; YONG-ZHEN, P.; XIAO-LIAN, W., SHU-YING, W. (2005). Intelligent control aeration and external carbonaddition for improving nitrogen removal. Environmental Modelling \& Software (in Press).

LEU H.G., LIN S.H.; SHYU C.C. and LIN C.M.,(1998). Effects of surfactants and suspended solids on oygen transfer under various operating conditions. Environment Technology. 19, 299-306.

LEWIS, W. K.; WHITMAN, W.G. (1924) - Principles of gas absortion. Industrial and Engineering Chemistry. v.16, n.12, p. 825-833. 
MEYBECK, M.; CHAPMAN, D.V.; HELMER, P. (1989). Global freshwater quality. A first assessment. Oxford. World Health Organization. Blackwell.

MEYBECK, M.; KIMSTACH, V.; HELMER, P. (1992). Strategies for water quality assessment. In: CHAPMAN, D. Water quality assessment. Cambridge, University press, p. 19-50.

MENDELSON, H.D. (1967). A.I.C.H.E. Journal, v.13, n.2, p.250.

METCALF; EDDY, INC. (1991). Inc. Wasterwater enginnering; Treatment, disposal, Reuse, 3nd. Ed., Singapore., Mc Graw-Hill Internacional Editions, 1334p.

MOTARJEMI, M e JAMESON, G. J. (1978). Chemical Engineering Science, v. 33, p.1415.

NEDER, G. B. (1994). Estudo do desempenho do aerador-misturador hiperbolóide e sua aplicabilidade no tratamento de águas residuárias, Dissertação de Mestrado, Departamento de Hidráulica e Saneamento, Escola de engenharia de São Carlos, Universidade de São Palo.

PEOT , W. A. (1969). Aeration of actived sludge in sewage treatment, Editor: D.L. Gibbon, Pergamon Press.

PÉREZ-CORREA, J.R.; LÓPEZ F.; SOLAR, I. (1991). Dissolved Oxygen Control through an Adaptive Non-Linear Model Approach: a Simulation Study. Journal of Process Control. Vol 1, Maio, p. 152-160.

PERRY, R. H. e GREEN, D. W. (1984) (eds), Perry`s Chemical engineers -Handbbok, McGraw - Hill, New York, 6. edição.

RATHBUN, R.E.; STEPHENS, D. W.; SCHULZ, D.; TAY, D.Y. (1978) - laboratoty studies of gas tracers for reaeration. Journal of the Environmental Engineering Division. ASCE. V.104, n.EE-2,p. 215-229, abr.

RICKER, N.L. (1985). Use of Quadratic Programming for Constrained Internal Model Control. Ind. Eng. Chem. Proc. Des. Dev., vol. 24, no 4.

RODRIGO, M.A.; SECO, A.; FERRER, J.; PENYA-ROJA, J.M., VALVERDE, J.L.. (1999). Nonlinear control of an activated sludge aeration process: use of fuzzy techniques for tuning PID controllers. ISA Transactions 38, pg. 231-241

SANDERS, P.A, ORLOB, G.T. (1987). Turbulent diffusion and the reaeration coefficient. Journal of the Sanitary engineering Division, v. 88, n. SA2, p. 53-83.

SCHROEDER, E. D. (1977). Water and wastewater treatment, McGraw-Hill, p.97.

SEBORG, D.E.; EDGAR, T.F.; MELLICHAMP, D. A. (1989) Process Dynamics and Control. Santa Bárbara, USA, John Wiley \& Sons, 716p.

SHIAU, C.C. (1995) Oxigen transfer in bubble and bubbleless aeration sistems, Ph D. thesis, University of Wollongong, Departament of civil and Mining Engineering. 
SILVA, J. A. (1994). Legislação ambiental. In: Direito Ambiental Constitucional. São Paulo, Malheiros Edit. Ltda, p.15-21.

SCHULZ, H. E. (1989). Investigação do mescanismo de reoxigenação da água em escoamento e sua correlação com o nível de turbulência junto à superfície. São Carlos. 516p. v.2. Tese (Doutorado em Hidráulica e Saneamento) - EESC - USP.

TRAORÉ, A.; GRIEU. S.; PUIG, S.; COROMINAS, L.; THIERY, F.; POLIT, M.; Colprim, J.. (2005). Fuzzy control of dissolved oxygen in a sequencing batch reactor pilot plant. Chemical Engineering Journal 111, pg. 13-19.

TREYBAL, R.E. (1981). Mass transfer operation, McGraw-Hill, London.

VIESSMAN, JR.W.; HAMMER, M.J.(1998). Water Supply and Pollution control, 6nd ed. U.S.A., Addison-Wesley, 827p.

VON SPERLING, M. 91997) Lodos ativados. Vol. 4. Departamento de Engenharia Sanitária e Ambiental, Universidade Federal de Minas Gerais.

WARD, R. C. et al. (1986). The "data-rich but information-poor" syndrome in water quality monitoring. Environmental Management, v.10, n.3,p.291-297.

WELTY, W.E. (1984). The two film Theory of Gas Absorption. Chemical and Metallurgical engineering. V. 29, n.4, pag. 146-149.

ZÄHRINGER, K. (1992). Grundlegende Untersuchungen der Dispergier-und Begasungseigenschaften eines neuartigen Hyperboloid-Rühr-und Begasungssystems, Diplomarbeit, LSTM-Erlangem.

ZIEMINSKI, S. A., CARON, M.; BLACKMORE, R. B.(1967) - Behavior o fair bubbles in dilute aqueous solutions. I \& EC fundam. 6, pp 233-242

ZIEMINSKI, S. A. e LESSARD, R. R. ( 1969). Effects of chemical additives on perfomance of na air-water contractor. I \& EC Process Des. Dev. 8, p. 69-74. 


\section{APENNDICE A}


Considere o sistema dado pela FIGURA A.1

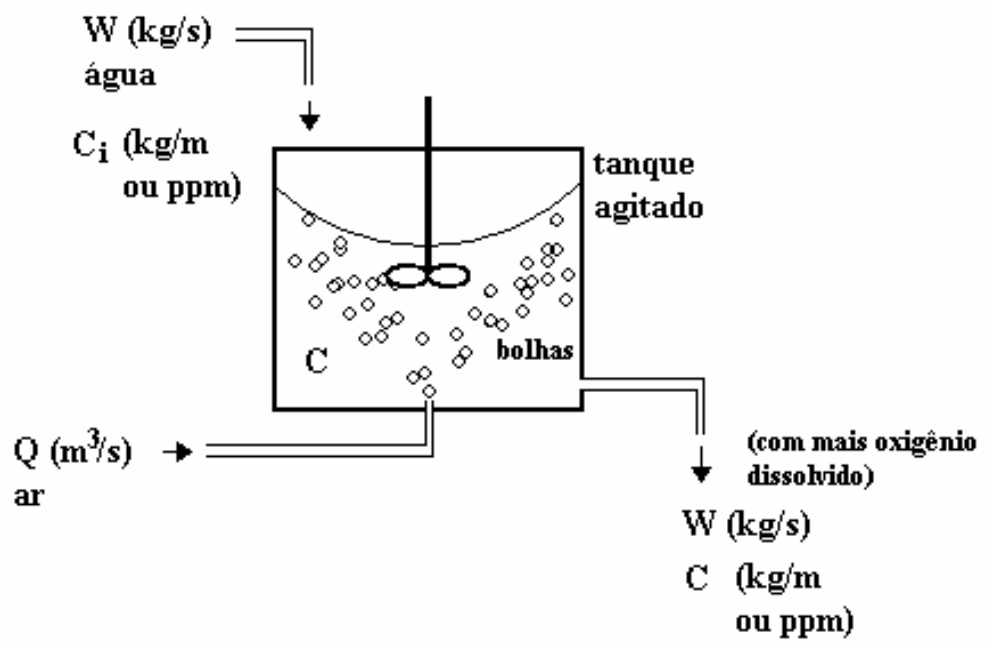

FIGURA A.1: Sistema de aeração com tanque agitado.

A água entra no tanque com uma concentração $C_{i}$ sujeita a variações ao longo do tempo, sendo sua vazão de $W \mathrm{Kg} / \mathrm{s}$. A aeração fornece uma quantidade de oxigênio $Q \mathrm{Kg} / \mathrm{s}$ elevando a concentração de oxigênio dissolvido na água do tanque para $C$. Se o tanque for bem agitado, a concentração na saída também será $C$, a qual é o objeto de estudo de controle. Entendendo a dinâmica do processo, ou seja, o comportamento das variáveis no tempo, temse pela conservação de massa por componente (oxigênio dissolvido):

$\mathrm{Ou}$

$$
\rho V \frac{d C}{d t}=W C_{i}-W C+Q
$$


Essa é a equação da dinâmica de dispersão do oxigênio no tanque. Trata-se de "regime transiente".

A solução dessa equação para uma variação abrupta em $Q\left(Q_{s 1} \rightarrow Q_{s 2}\right)$ é chamada resposta ao degrau (FIGURA A.2):

$C=K_{p} A\left(1-e^{-\frac{t}{\tau}}\right)$

Onde $K_{p}$ é o ganho do processo em estado estacionário (ou regime permanente) ou:

$K_{p}=\frac{\Delta \text { resposta }}{\Delta \text { entrada }}=\frac{C_{s 2}-C_{s 1}}{Q_{s 2}-Q_{s 1}}$

Sendo $A$ a amplitude do degrau realizado na variação de $Q$ (no caso, pode ser $A=Q_{s 2}-Q_{s 1}$ ). O parâmetro $\tau$ é a constante de tempo do processo com as mesmas unidades de tempo adotadas (s, min, h, etc).

$\tau=\frac{\rho V}{W}$ 


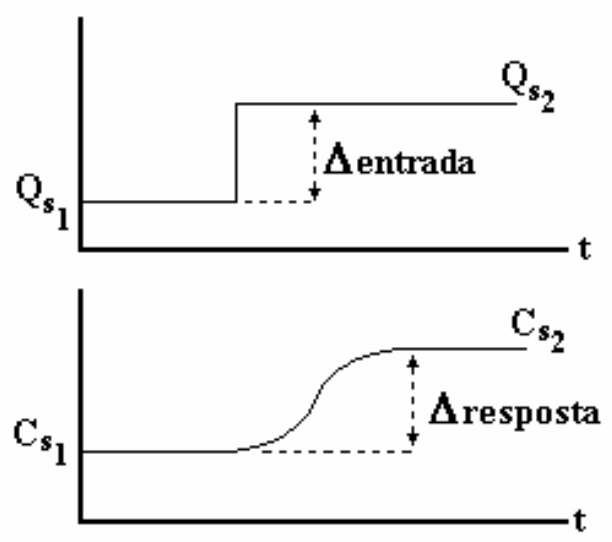

FIGURA A.2: Sistema de aeração com tanque agitado.

Partindo do equilíbrio estabelecido ou "regime permanente" definido em uma etapa de projeto, essa seria a "condição operacional" desejada para o qual o sistema foi construído. Então, como nesse ponto não existe o transiente, tem-se

$0=W\left(C_{i S}-C_{S}\right)+Q_{S}$

$Q_{S}=W\left(C_{S}-C_{i S}\right)$

Onde $C_{s}$ é a concentração desejada no projeto do sistema. $Q_{s}$ é a taxa de alimentação de oxigênio definida no projeto assim como $C_{i s}$ é a concentração, também definida para o projeto.

Uma vez projetado, os sistema teria que funcionar para as condições impostas perfeitamente, mas por algum motivo (natureza, operação, delimitações físicas, etc) o sistema está sujeito a distúrbios os quais podem fazer o processo ir para outras condições não satisfatórias. Tais distúrbios podem ser: 
- variável de entrada incontrolada, oscilante, ou com variações imprevisíveis (no caso $C_{i}, W$ ou até mesmo $Q$ )

- mudança de nível operacional, forçando um novo equilíbrio para o sistema.

Com o sistema sem nenhum recurso de controle, qualquer um desses distúrbios poderia inviabilizar o processo (considerando os pontos desejados). Uma opção seria colocar um operador treinado para observar a temperatura de saída e tentar mantê-la o mais próximo possível do valor desejado, manipulando a potência elétrica no aquecimento.

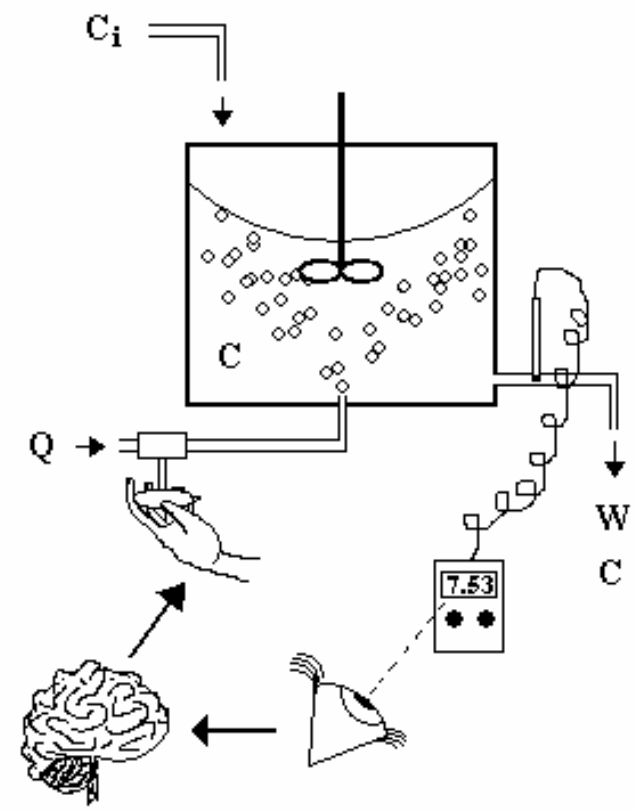

FIGURA A.3: Controle manual baseado na experiência do operador.

Outra opção seria colocar um sistema de controle automático baseado em cálculos de desvios ou erros entre a variável medida (ou controlada) e o valor desejado. 


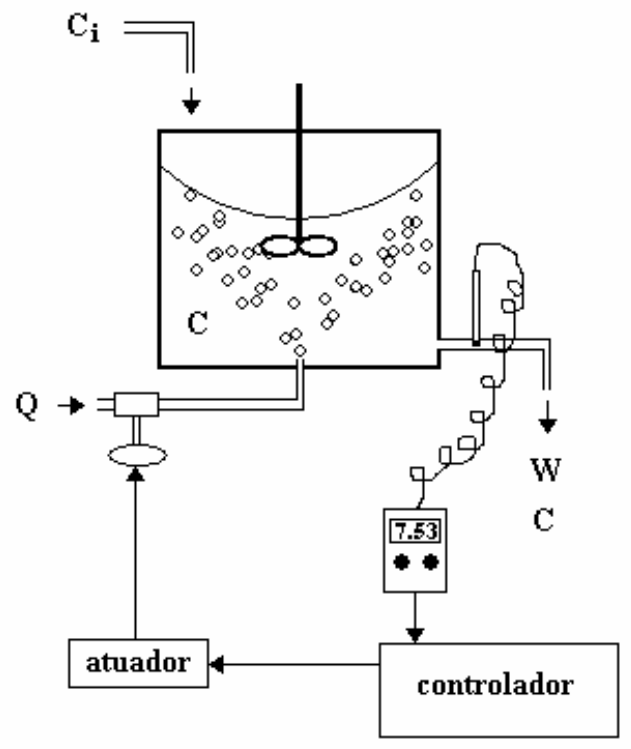

FIGURA A. 4: Controle automático baseado em algoritmos.

A segunda opção é mais atrativa por efetuar um controle mais efetivo. Então quais os modos de controle automático que podem ser empregados satisfatoriamente? São vários, desde um simples liga-desliga até técnicas avançadas de otimização. O objeto desse estudo é o controle convencional PID que é um algoritmo de três termos (Proporcional - Integral Derivativo) para minimizar o desvio da "variável desejada" ou "set-point".

Sabemos que teríamos que regular $Q$ manualmente para compensar desvios em $C$, então $Q$ é a "variável manipulada". É sobre $Q$ que o controlador irá operar, sendo essa variável a saída do controlador e o desvio $e=C_{s}-C$ a entrada (FIGURA A.5).

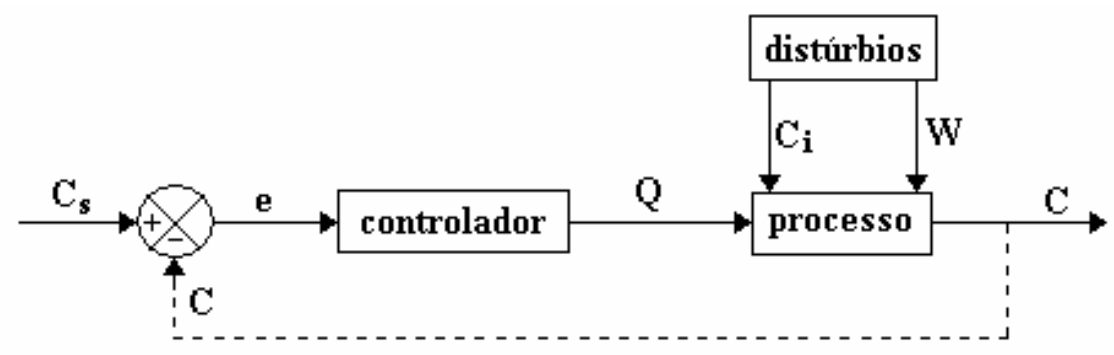


FIGURA A.5: Esquema do processo de aeração no tanque com controle baseado no desvio $e=C_{s^{-}} C$.

Segue uma análise introdutória sobre o controlador PID com relação aos seus três termos:

\section{P - Proporcional}

Ao considerar somente controle proporcional, tem-se

$Q=Q_{S}+K e$

Onde

$Q=W\left(C_{S}-C_{i S}\right)$

$e=C_{S}-C$

O que se tem são "ações de controle", $Q$, proporcionais ao desvio $e . K$ é a constante proporcional (ou $\left.K_{c}\right)$.

É possível verificar que quanto maior $K$, mais perto se chega do valor desejado (Figura A.6). 


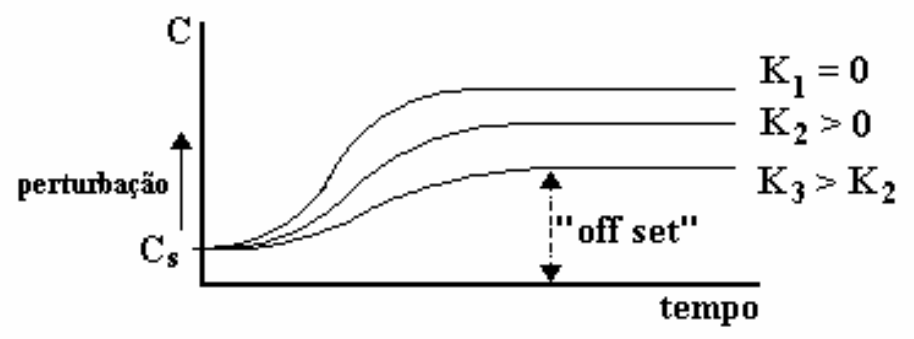

FIGURA A.6: Comportamento do controle $\mathrm{P}$ ao variar $K$.

O problema surge para valores indevidamente elevados de $K$ denotado pela amplificação de ruídos, os quais seriam naturalmente amortecidos pelo sistema. Suponha um ruído em $C i$. Observa-se pela FIGURA A.7 a amplificação ocasionada pelo controle P.
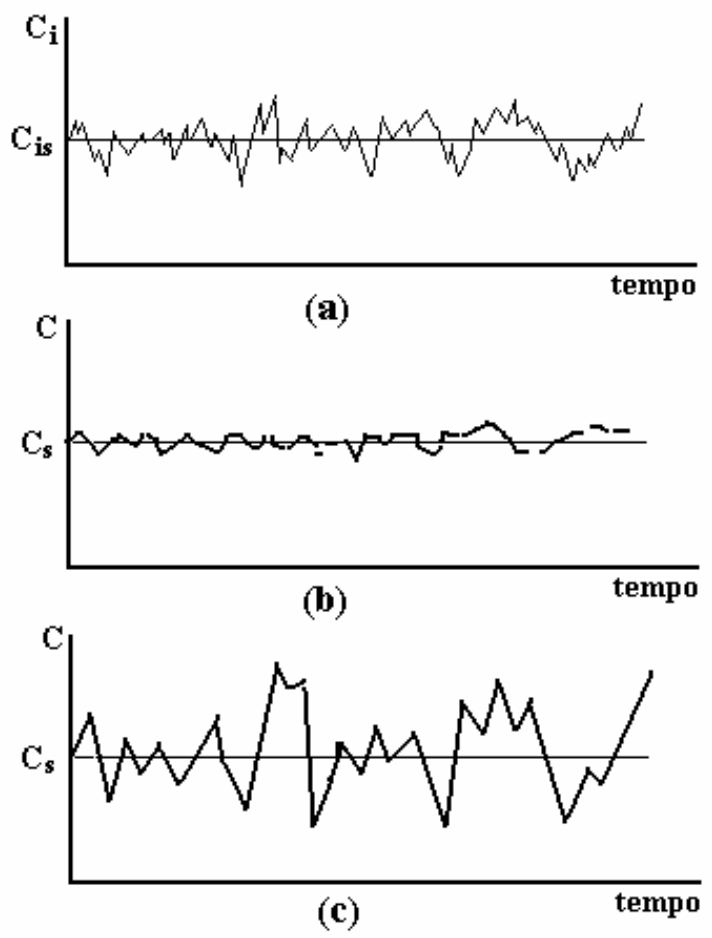
FIGURA A.7: Amplificação demasiada dos movimentos de controle P. (a) distúrbio na concentração de entrada. (b) resposta naturalmente amortecida sem o controle P. (c) controle $\mathrm{P}$ atuando e amplificando demasiadamente os desvios na resposta.

\section{PI - Proporcional Integral}

Acrescenta-se uma parcela que integraliza os desvios ao longo do tempo.

$$
Q=Q_{S}+K e+\frac{K}{\tau_{I}} \int_{0}^{t} e d t
$$

Onde $\tau_{I}$ é chamada constante de tempo integral. Neste caso, é necessário ajustar $K$ e $\tau_{I}$. O comportamento da resposta $C$ variando-se $\tau_{I} \operatorname{com} K$ fixo tem a forma dada pela FIGURA A.8.

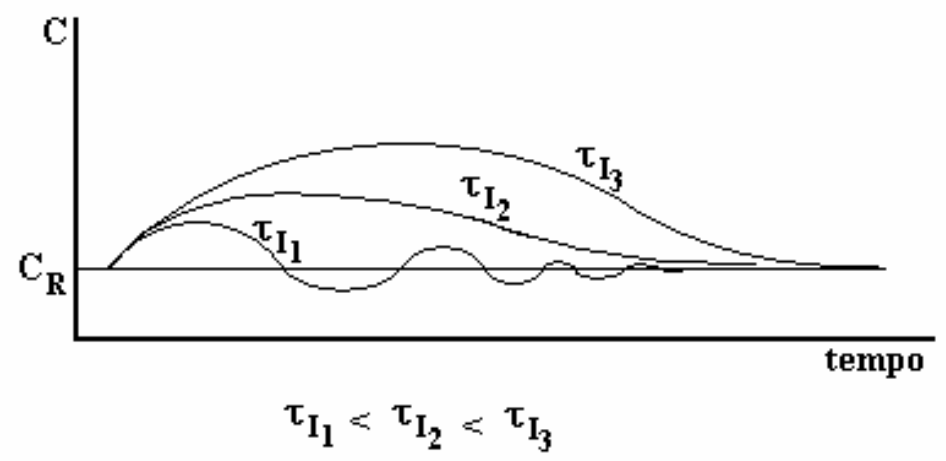

FIGURA A.8: Comportamento do controle PI ao variar $\tau_{I} \operatorname{com} K$ fixo.

Para $\tau_{I}>0, e$ sempre será nulo após o re-estabelecimento do regime. Assim, não seriam mais necessários valores elevados de $K$. 
Evidentemente, a escolha de $\tau_{I}$ ficaria entre $\tau_{I 1}$ e $\tau_{I 2}$.

- Para $\tau_{12}, C$ se assenta mais rapidamente, mas o erro máximo (“overshoot”) é grande comparado a $\tau_{I 1}$.

- Para $\tau_{I 1}, C$ é mais demorado com resposta oscilatória, mas sempre com erros (inclusive "overshoot") bem inferiores.

\section{PID - Proporcional Integral Derivativo}

Produz um efeito de antecipação na variação do erro devido à introdução do termo derivativo.

$$
Q=Q_{S}+K e+\frac{K}{\tau_{I}} \int_{0}^{t} e d t+K \tau_{D} \frac{d e}{d t}
$$

Onde $\tau_{D}$ é a constante de tempo derivativa.

A FIGURA A.9 mostra o comportamento de um PID com variações em $\tau_{D}$.

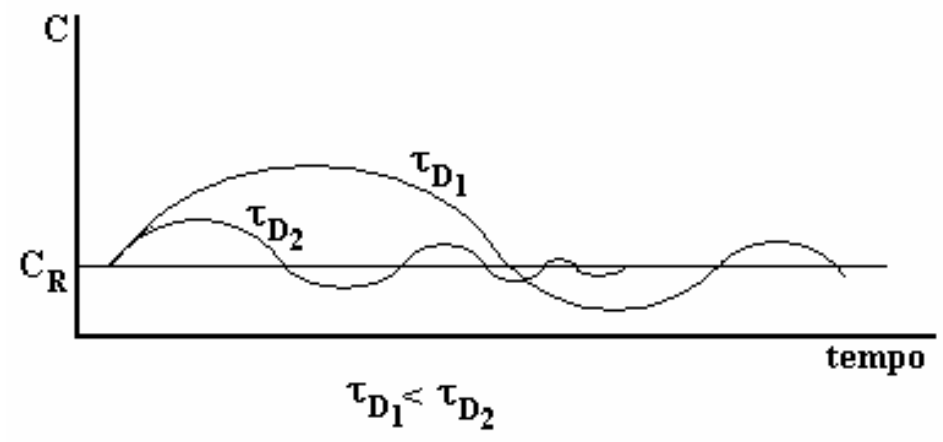

FIGURA A.9: Comportamento do controle PID ao variar $\tau_{D} \operatorname{com} \tau_{I}$ e $K$ fixos. 
A adição da ação derivativa na ação de PI promove uma sensível melhora na resposta.

Se a resposta de PI é oscilatória, o PID traz o assentamento mais rápido com menor oscilação (FIGURA A.10).

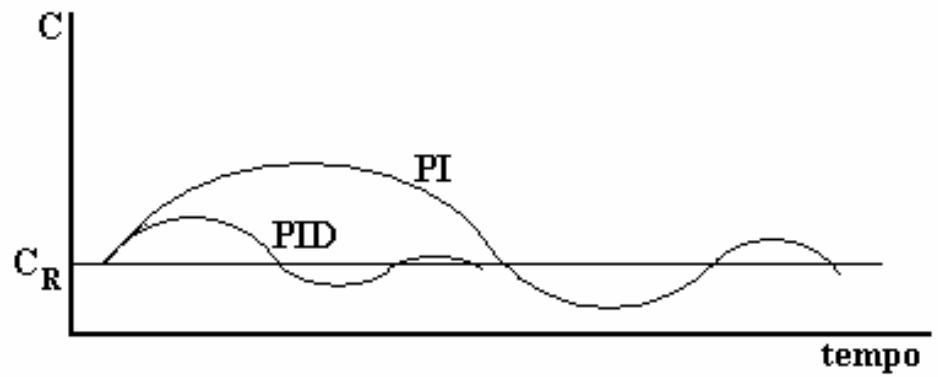

FIGURA A.10: Comportamento do controle PID ao variar $\tau_{D}$ com $\tau_{I}$ e $K$ fixos.

Enfim, o projeto baseia-se em escolher $K, \tau_{I}$ e $\tau_{D}$ para um controle adequado.

\section{Algoritmos Digitais do PID}

A equação do PID (EQUAÇÃO A.12) está na forma analítica e para implementação “on-line" faz-se necessário uma forma discretizada. As medidas são pontuais em intervalos de tempos definidos e não uma medida contínua, conforme mostra a FIGURA A.11. 


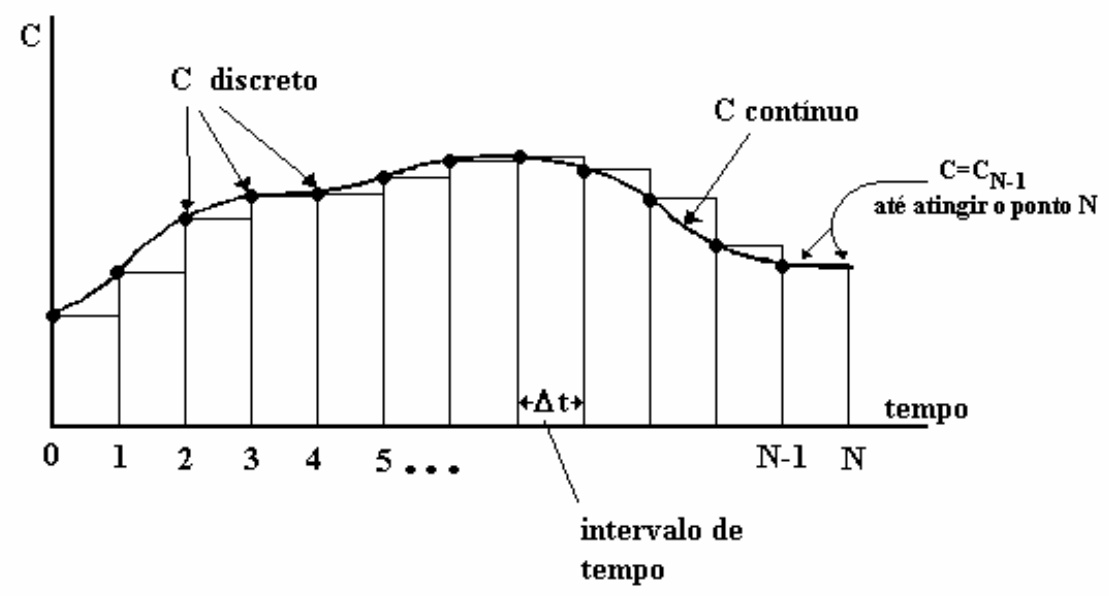

FIGURA A.11: Comparação entre as medidas discretas com intervalo de amostragem $\Delta t \mathrm{e}$ medida contínua no tempo.

Aproximando a integral de um somatório

$$
\int_{0}^{t} e d t=\sum_{k=1}^{N} e_{k} \Delta t=\left(e_{1}+e_{2}+e_{3}+\ldots+e_{N}\right) \Delta t=\Delta t \sum_{k=1}^{N} e_{k}
$$

Onde $N$ é o número total de intervalos $\Delta t$ até completar o tempo $t$ atual

$$
\begin{aligned}
& t=N . \Delta t \\
& d t \cong \Delta t
\end{aligned}
$$

Aproximando a derivada por uma "diferença atrasada"

$$
\frac{d e}{d t}=\frac{\Delta e}{\Delta t}=\frac{e_{N}-e_{N-1}}{\Delta t}
$$

Teremos então: 


$$
Q_{N}=Q_{S}+K\left[e_{N}+\frac{\Delta t}{\tau_{I}} \sum_{k=1}^{N} e_{k}+\frac{\tau_{D}}{\Delta t}\left(e_{N}-e_{N-1}\right)\right]
$$

Essa é conhecida como forma "posição" do PID.

Uma formulação mais vantajosa e mais aplicada é a formulação "velocidade". Para tal, explicitamos $Q_{N-1}$ na formula "posição" e fazemos:

$$
\Delta Q=Q_{N}-Q_{N-1}
$$

Que é aplicado diretamente na saída do controlador. $\Delta Q$ é a chamada "ação" ou "movimento" de controle. Então:

$$
Q_{N-1}=Q_{S}+K\left[e_{N-1}+\frac{\Delta t}{\tau_{I}} \sum_{k=1}^{N-1} e_{k}+\frac{\tau_{D}}{\Delta t}\left(e_{N-1}-e_{N-2}\right)\right]
$$

$\mathrm{e}$

$$
\Delta Q=Q_{N}-Q_{N-1}=K\left[\left(e_{N}-e_{N-1}\right)+\frac{\Delta t}{\tau_{I}} e_{N}+\frac{\tau_{D}}{\Delta t}\left(e_{N}-2 . e_{N-1}+e_{N-2}\right)\right]
$$

Vemos que $\Delta Q$ é baseado somente em desvios de três intervalos de tempo consecutivos. Então podemos fazer

$$
\Delta Q=K e_{N}-K e_{N-1}+\frac{K \Delta t}{\tau_{I}} e_{N}+\frac{K \tau_{D}}{\Delta t} e_{N}-\frac{2 K \tau_{D}}{\Delta t} e_{N-1}+\frac{K \tau_{D}}{\Delta t} e_{N-2}
$$


ou

$\Delta Q=\left(K+\frac{K \Delta t}{\tau_{I}}+\frac{K \tau_{D}}{\Delta t}\right) e_{N}+\left(-K-\frac{2 K \tau_{D}}{\Delta t}\right) e_{N-1}+\left(\frac{K \tau_{D}}{\Delta t}\right) e_{N-2}$

ou ainda

$\Delta Q=\alpha_{1} e_{N}+\alpha_{2} e_{N-1}+\alpha_{3} e_{N-2}$

sendo

$$
\begin{aligned}
& \alpha_{1}=K\left(1+\frac{\Delta t}{\tau_{I}}+\frac{\tau_{D}}{\Delta t}\right) \\
& \alpha_{2}=-K\left(1+\frac{2 \tau_{D}}{\Delta t}\right) \\
& \alpha_{3}=\frac{K \tau_{D}}{\Delta t}
\end{aligned}
$$

Sempre que o PID é reiniciado, $e_{N-1}=e_{N-2}=0$ e $Q_{N}=Q_{0}=Q_{s}$ (valor operacional já definido).

\section{Técnicas para projetar o PID}

Existem várias técnicas para obter valores de $K, \tau_{I}$ e $\tau_{D}$. Umas mais simples e aproximadas (até mesmo tentativa e erro) e outras mais sofisticadas com maior embasamento teórico. Seborg et al. (1989) apresenta alguns métodos. Talvez, o mais indicado seja aquele 
baseado em critério de integral do erro, especificamente, o ITAE ("Integral of the Timeweighted Absolute Error" ou "Integral do erro absoluto ponderado no tempo") dado por

$\operatorname{ITAE}=\int_{0}^{\infty} t|e(t) d t|$

As relações de projeto para que o ITAE seja minimizado, considerando modelo de $1^{\text {a }}$ ordem com atraso, estão descritos na TABELA A.1 sendo necessário o uso das equações a seguir para avaliar $K, \tau_{I}$ e $\tau_{D}$.

$M=A\left(\frac{\theta}{\tau}\right)^{B}$

$\mathrm{Na}$ qual

$M=K \cdot K_{p}$

no termo Proporcional;

$M=\tau / \tau_{I}$

no termo Integral;

$M=\tau_{D} / \tau$

no termo Derivativo. 
Especificamente, para mudança de "set point" (em negrito na TABELA A.1), somente para o termo Integral tem-se

$\tau / \tau_{I}=A+B\left(\frac{\theta}{\tau}\right)$

TABELA A.1: Relações de projeto de controle PID através do critério ITAE para processo de $1^{\text {a }}$ ordem com atraso.

\begin{tabular}{ccccc}
\hline perturbação & modo & termo & $\boldsymbol{A}$ & $\boldsymbol{B}$ \\
\hline carga & PI & P & 0,859 & $-0,977$ \\
& & I & 0,674 & $-0,680$ \\
carga & PID & P & 1,357 & $-0,947$ \\
& & I & 0,842 & $-0,738$ \\
& & D & 0,381 & 0,995 \\
set point & PI & P & 0,586 & $-0,916$ \\
& & I & $\mathbf{1 , 0 3}$ & $\mathbf{- 0 , 1 6 5}$ \\
set point & PID & P & 0,965 & $-0,85$ \\
& & I & $\mathbf{0 , 7 9 6}$ & $\mathbf{- 0 , 1 4 6 5}$ \\
& & D & 0,308 & 0,929 \\
\hline
\end{tabular}

Fonte: Seborg et al. (1989)

Tempo morto, tempo de atraso ou retardo

É o tempo que a resposta leva para iniciar o efeito de um distúrbio na entrada. Considere um longo tubo onde, em $t=0$, coloca-se um corante na entrada (FIGURA A.12).

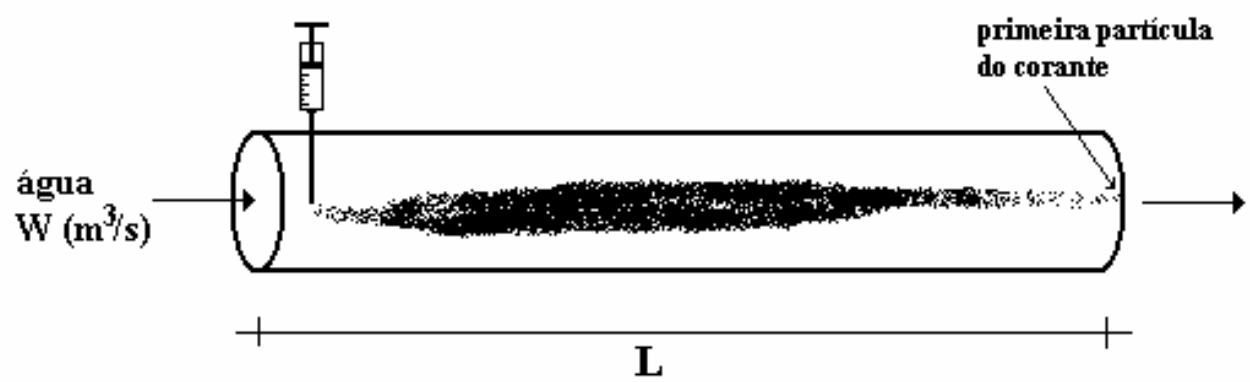


FIGURA A.12: Ilustração da ocorrência do retardo sobre o escoamento de traçador dentro de um duto. A primeira partícula do corante a sair define o tempo morto como o tempo decorrido durante seu trajeto desde a injeção.

Observa-se que a primeira partícula do corante demora $\theta$ (s, min, h, etc) para chegar até o final do tubo de comprimento $L$. O corante acompanha o fluxo de água. Então, $\theta$ é simplesmente o tempo necessário para uma partícula percorrer $L$, ou seja

$\theta=\frac{\text { volume do tubo }}{\text { vazão volumétrica }}=\frac{V}{W}=\frac{A \cdot L}{W}$

A relação entre a entrada e saída para um processo com atraso é:

$y(t)=x(t-\theta)$

saída entrada

Esquematicamente, tem-se (FIGURA A.13).

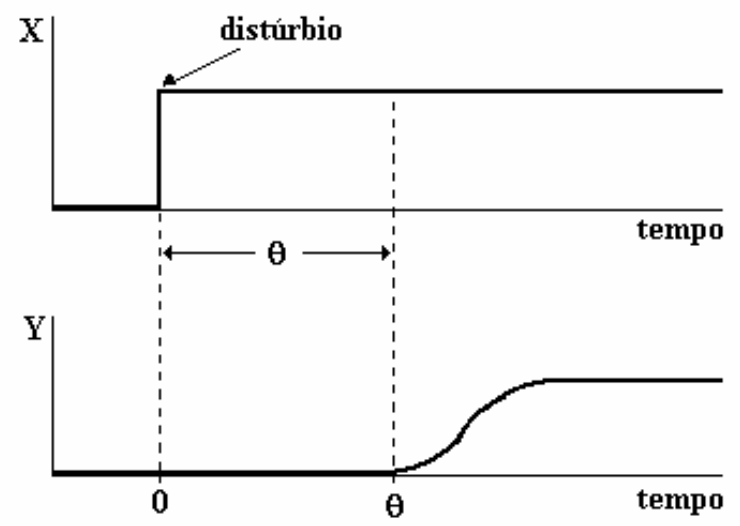

FIGURA A.13: Histórico de uma resposta com tempo de atraso. A saída demora $\theta$ para iniciar a elevação. 
A solução analítica para um processo de $1^{\mathrm{a}}$ ordem com tempo morto é dada por:

$$
y=K_{p} A\left[1-e^{\frac{-(t-\theta)}{\tau}}\right]
$$

similar àquela vista para o tanque aquecido.

A presença do tempo morto no processo pode gerar instabilidades ao fechar a malha com controlador PID. Portanto, é necessário adotar critérios de projeto que levem em conta essa influência.

\section{Dinâmica do sensor}

Possivelmente, a resposta que um sensor fornece não é o valor real da variável para aquele momento. Todo sensor obedece uma certa dinâmica (que pode ser considerada de $1^{\text {a }}$ ordem) que torna a medição lenta. Na maioria das vezes, isso é negligenciado, e o controlador, quando implementado, gera oscilações, instabilidades e até mesmo inviabilidade no PID. Para contornar esse problema, temos que considerar Processo+Sensor como um sistema de dinâmica única e sobre ele projetar o controlador (FIGURA A.14). 


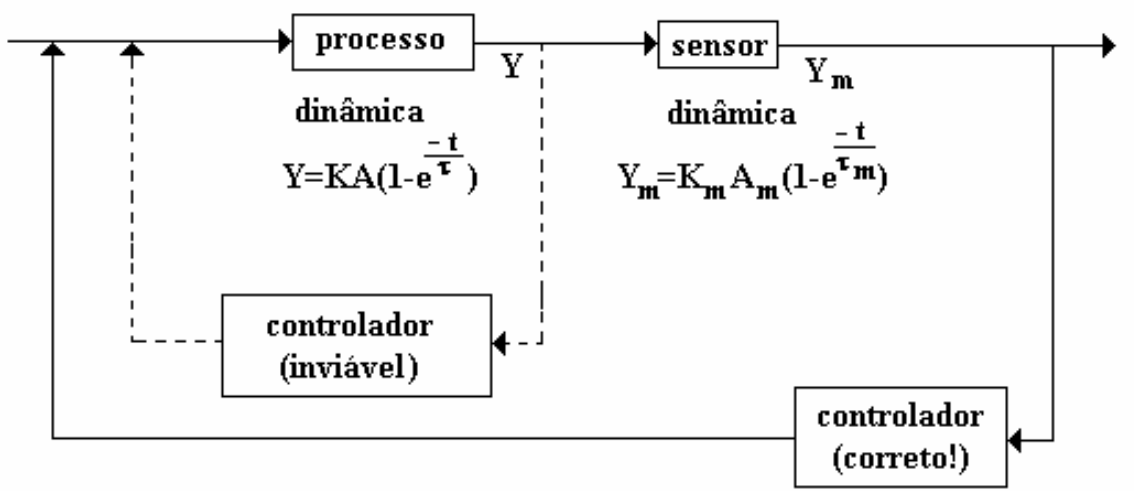

FIGURA A.14: Diagrama de blocos evidenciando o modo correto de projetar um controlador levando em conta a dinâmica do sensor. 